\title{
Doxycycline, an anti-inflammatory agent, alleviates dyskinesia induced by L-DOPA in Parkinsonian rats
}

\author{
Mariza Bortolanza ${ }^{1}$, Glauce Nascimento ${ }^{2}$, Rita Raisman-Vozari ${ }^{3}$, and Elaine Del Bel ${ }^{4}$ \\ ${ }^{1}$ Department of Basic and Oral Biology, Faculty of Odontology of Ribeirao Preto, \\ University of Sao Paulo (USP), Av do Café s/n; Brazil \\ ${ }^{2}$ Faculty of Odontology of Ribeirao Preto, University of Sao Paulo (USP), Av do Café s/n; \\ Brazil; Tel: +55 1633154050 \\ 32Sorbonne Universite, UPMC Univ Paris 06, INSERM, CNRS, UM75, U1127, UMR 7225, \\ Institut du Cerveau et de la Moelle Epinière, Paris, France \\ ${ }^{4}$ University of Sao Paulo Faculty of Dentistry of Ribeirao Preto
}

June 22, 2020

\begin{abstract}
Background and Purpose L-DOPA induced dyskinesia is a debilitating side effect of treating Parkinson's disease with L-DOPA. There is a need to discover a treatment that has the same benefits as L-DOPA treatment without the associated side effects. Here, we demonstrate the anti-dyskinetic potential of doxycycline and the analog compound COL-3 (without antimicrobial activity) in hemiparkinsonian rats presenting L-DOPA-induced dyskinesia. Experimental Approach Wistar adult male rats received a unilateral medial forebrain bundle injection of 6-hydroxydopamine and were then orally administered L-DOPA once a day for 14 days. This resulted in dyskinetic-like behavior. Key Results A single injection of doxycycline (intraperitoneal) or COL-3 (intracerebroventricular) together with L-DOPA attenuated the dyskinesia. Co-treatment with doxycycline from the first day of L-DOPA suppressed the onset of dyskinesia. The improved motor responses to L-DOPA remained intact in the presence of doxycycline or COL-3, indicating the preservation of the L-DOPA benefits. Doxycycline treatment was associated with decreased expression of FosB, cyclooxygenase-2, astrocytes, and microglia, which had previously been found to be elevated in the basal ganglia of rats exhibiting dyskinesia. In addition, metalloproteinase-2/-9 activity, metalloproteinase- 3 expression, and production of reactive oxygen species in the basal ganglia of dyskinetic rats showed a significant positive correlation with the intensity of dyskinesia, which was decreased with the doxycycline treatment. Conclusion and Implications Given the longestablished and safe use of doxycycline and the similar effect of COL-3 (without antimicrobial activity), this study indicates that both drugs should undergo testing for their ability to reduce signs of dyskinesia induced by L-DOPA in patients with Parkinson's disease.
\end{abstract}

\section{Bullet point summary:}

'What is already known',

Repeated treatment with L-DOPA induces dyskinesia (LID) in patients with Parkinson's disease (PD).

Doxycycline is a clinically used antibiotic that posses dopamine neuroprotective properties and antiinflammatory activity.

'What this study adds'

Doxycycline reduced and prevented LID in a rat model of PD preserving L-DOPA motor benefits. 
Doxycycline decreased striatal neuroinflammatory signals, metalloproteinase changes, and ROS production associated with LID.

\section{'Clinical significance'}

Adjunct treatment to L-DOPA might delay the onset of dyskinesia and attenuate neurodegeneration.

Doxycycline or its derivatives should undergo testing in patients with Parkinson's disease.

\section{INTRODUCTION (996 words)}

Parkinson's disease (PD) is a progressive, age-associated neurodegenerative disorder characterized by a depletion of dopamine in the striatum due to the loss of dopaminergic neurons of the substantia nigra compacta (SNc; Fahn et al., 2004; Olanow et al., 2004). L-DOPA (3,4-dihydroxyphenyl-L-alanine) is considered the most effective and well-tolerated noninvasive therapy for the treatment of PD motor symptoms. However, over time this effect decreases and more than $75 \%$ of L-DOPA-treated PD patients develop incapacitating abnormal involuntary movements (AIMs) referred to as L-DOPA-induced dyskinesia (LID) (Aquino and Fox, 2015; Cenci et al., 2020; Cenci and Olanow, 2017; Espay et al., 2018; Fahn et al., 2004; Olanow et al., 2004). As such, there has been a number of studies conducted to try and find alternative therapies that do not result in the pro-dyskinetic side effects or can reduce the dyskinetic signs.

The mechanisms involved in the pathogenesis of LID are complex and are not entirely understood. In the nigrostriatal circuitry, there are several alterations associated with LID manifestation, for example, the expression of specific genes (ERK1/2 extracellular signal-regulated kinase 1/2; DARP32 dopamine- and cAMP-regulated neuronal phosphoprotein; Fos, Finkel-Biskis-Jinkins osteosarcoma) (Cenci et al., 2007; Cenci, 2014; Cenci and Crossman 2018; You et al., 2018), and altered synaptic plasticity (Cenci et al., 2007, 2020; Cenci, 2014) with modifications in the long-term potentiation of the cortico-striatal pathway (Borgkvist et al., 2018; Calabresi et al., 2015; Picconi et al., 2011; 2003). Pre-clinical and clinical evidence has emerged to support the use of a number of compounds to treat LID. Amantadine (the non-selective N-methyl-Daspartate receptor antagonist - Blanchet et al., 1998; Lundblad et al., 2002) is the only compound with robust evidence of anti-dyskinetic effects in patients. However, its therapeutic success is limited (Bortolanza et al., 2015; Cenci et al., 2020; 2014).

Various neural pathways such as the serotonin, acetylcholine, $\gamma$-aminobutyric acid, nitric oxide, or cannabinoid interact with dopaminergic pathways have been proposed as possible pharmacological targets for LID suppression (Dos-Santos-Pereira et al., 2016; Espadas et al., 2020; Huot et al., 2013; Johnston et al., 2018; Vijayakumar and Jankovic, 2016). In rodent PD models, neuroinflammation has been reported to be associated with the development and onset of LID (Barnun et al., 2008; Boi et al., 2019 Bortolanza et al., 2015 a, b; Munoz et al., 2014; Mulas et al., 2016; for review see Del Bel et al., 2016; Carta et al., 2017). In pre-clinical studies, pharmacological based therapy with anti-inflammatory compounds as corticosterone (Barnum et al., 2008), cannabidiol (dos-Santos-Pereira et al., 2016, Espadas et al., 2020), nitric oxide synthase inhibitor (Bortolanza et al., 2016; Padovan-Neto et al., 2009, 2015; Solís et al., 2015), thalidomide (Boi et al., 2019; Mulas et al., 2016), or IRC-82451 a multitargeting molecule (Aron-Badin et al., 2013), reduced the severity of dyskinesia and was associated with a reduction in inflammation. Amantadine may also be somewhat beneficial by inhibiting the inflammatory activation of microglia (Kim et al., 2012).

Recently, it was hypothesized that the striatum in LID, evolves from the combination of dopaminergic terminals degeneration, inadequate dopamine presence following the administration of L-DOPA and excessive glutamate concentration (Barcia et al., 2003; McGeer et al., 2003; Picconi et al., 2011; 2003; Tansey et al., 2007). In vivo brain imaging of patients with $\mathrm{PD}$ reveals an association between widespread microglial activation and the pathological process (Bartels et al., 2007; Gerhard et al., 2006; Ouchi et al., 2005). Inflammatory reaction in the basal ganglia of both parkinsonian rats and patients with PD that have a history of dyskinesia also revealed angiogenesis, vascular endothelial growth factor up-regulation and altered brainblood barrier properties (Janelidze et al., 2015; Lerner et al., 2017; Ohlin et al., 2011, 2012). Furthermore, long after the neurotoxin, 6-hydroxydopamine (6-OHDA) has been cleared from the brain the striatum of 
lesioned rats receiving L-DOPA treatment displayed sustained neuroinflammation and neurodegeneration (Bortolanza et al., 2015a and b; Muñoz et al., 2014; Spinnewyn et al., 2011; Teema et al., 2016). Therefore, targeting neuroinflammation might be a pharmacological strategy to limit LID (Del Bel et al., 2016; Huot et al., 2013;).

Tetracycline antibiotics are increasingly being used, largely due to their anti-inflammatory features (Bortolanza et al., 2018; Reglodi et al., 2017). The second-generation tetracycline antibiotic, doxycycline (6-deoxy-5hydroxytetracycline, a Food and Drug Administration approved compound), protects dopaminergic neurons from degeneration induced by 6-OHDA (Lazzarini et al., 2013), 1-methyl-4-phenyl-1,2,3,6-tetrahydropyridine (MPTP, Du et al. 2001; Wu et al. 2003) and lipopolysaccharide (LPS, Zhang et al., 2015). This neuroprotective effect seems to be associated with its anti-inflammatory properties (Lazzarini et al., 2013; Stoilova et al., 2013). At a clinical level, the therapeutic rationale for targeting inflammation in PD is supported by the observation of the reduced incidence of PD in patients using tetracycline for rosacea treatment (Egeberg et al., 2016). Moreover, these rosacea patients did not present any prominent side effects related to the antimicrobial activity (Gompels et al. 2006; Langevitz et al. 1992; NINDS NET-PD Investigators 2006; Payne et al. 2011; Smith et al. 2011). Although it is unclear what drives increased inflammation in patients with PD, tetracycline and analog compounds have emerged as a potential treatment for PD and other neurodegenerative disorders (Johnston et al., 2019; Socias et al., 2018).

Due to the well-known anti-inflammatory effects of doxycycline, we hypothesized that this drug might reduce LID displayed inflammatory processes and, as a result, alleviate the expression of LID. In addition, to avoid side effects, such as bacterial resistance, COL-3 (CMT-3,6-demethyl-6-deoxy-4-de[dimethylamino]tetracycline formerly known as incyclinide) a chemically modified tetracycline (Edan et al., 2013; Liu et al., 2001) might be efficacious in the treatment of LID.

In the present study, we examined the potential effect of doxycycline and COL-3 to modify LID induced by chronic L-DOPA treatment in 6-OHDA lesioned rats. We analyzed whether doxycycline and/or COL-3 given once dyskinesia was already present decreased dyskinetic signals and also whether the co-administration of doxycycline with L-DOPA from day one inhibited the appearance of LID. Using an immunohistochemistry analysis, we examined dopamine depleted striatum changes due to L-DOPA and doxycycline treatment.

\section{METHODS}

Animals Male Wistar rats ( $\mathrm{n}=270$ ) FMRP-USP, Ribeirao Preto, Brazil; 200-250 g body weight) were housed and maintained in groups of three per cage in a controlled environment under a light-dark cycle of $12 \mathrm{~h}$ (lights on at 06:00 and off at 18:00 h), in a quiet room with controlled temperature $\left(23{ }^{\circ} \mathrm{C} \pm 1\right.$ $\left.{ }^{\circ} \mathrm{C}\right)$. All experimental animal procedures were approved by the local Animal Care and Use Committee of the University of São Paulo/Brazil at the Ribeirao Preto Campus (2016.1.667.58.4) and were conducted in accordance with the Guide for the Care and Use of Laboratory Animals of the National Council for the Control of Animal Experimentation (CONCEA).

\section{Experimental Parkinsonism and dyskinesia}

Dopaminergic neuronal lesion with 6-OHDA: Rats were rendered hemiparkinsonian as previously described (Gomes and Del Bel, 2003; Gomes et al., 2008; Padovan-Neto et al., 2015; Padovan-Neto et al., 2009;). The animals $(\mathrm{n}=270)$ were anesthetized with 2,2,2-tribromoethanol (Sigma-Aldrich, St. Louis, MO, USA) (250 mg kg-1, i.p.) and fixed into a stereotaxic frame (David Kopf, model USA, 9:57) with the incisor bar set at $3.3 \mathrm{~mm}$ below the interaural line. The rats received one deposit (coordinates from bregma in mm: AP $=-4.3 ; \mathrm{LL}=-1.6 ; \mathrm{DV}=-8.3$ ) of $2.0 \mu \mathrm{l}$ 6-OHDA (Sigma-Aldrich, St Louis, MO, USA) into the left medial forebrain bundle as described by Gomes et al. (2008) (6-OHDA - $2.5 \mu \mathrm{g} \mu \mathrm{l}-1$ in $0.9 \% \mathrm{NaCl}$ supplemented with $0.02 \%$ ascorbic acid, $1 \mu \mathrm{L}$ min-1). Following surgery, all rats were placed in clean cages on a warming pad for recovery $(60 \mathrm{~min})$, after which they were returned to group housing. A non-lesioned control group $(\mathrm{n}=24)$ was also included.

Two weeks later, the extent of the 6-OHDA-induced injury to the dopaminergic neurons was estimated 
using an apomorphine-induced rotation test $(0.5 \mathrm{mg} \mathrm{kg}-1$ in $0.9 \% \mathrm{NaCl}$, subcutaneous [s.c.], Sigma). Motor asymmetry was assessed using an automated system (Columbus Instruments International, Ohio, USA; Ungerstedt and Arbuthnott, 1970). Only those rats showing $>90$ total full contralateral turns over 45 min were selected for the study. Rats meeting this criterion have been reported to have a greater than $95 \%$ depletion of striatal dopamine (Chang et al., 1999; Kirik et al., 1998; Robinson and Becker 1983).

The lesion was confirmed histologically at the end of the behavioral tests by tyrosine hydroxylase (TH) immunohistochemistry. This confirmed that all rats in this study had more than $90 \%$ of diminution in $\mathrm{TH}$ immunoreactivity both in the dopamine depleted striatum and in the SNc.

Drug treatment The dosage regimen and routes of administration were based on previously published studies (Cenci et al., 1998; LazzarinI et al., 2013; Padovan et al., 2009; Worlitzer et al., 2013).

The preparation of L-DOPA used for animals was given orally as it is currently used for treating patients with PD. The concentration $\left(20 \mathrm{mg} \mathrm{kg}^{-1}\right)$ is similar to the usual regimen of L-DOPA in patients ranging from 0.2 to $1.6 \mathrm{~g} /$ day, which corresponds to about 1-20 mg kg-1 in animal models (Charvin et al., 2018; Lundblad et al., 2004). However, L-DOPA has low bioavailability when administered orally in comparison with the intraperitoneal route (Bredberg et al., 1994; Kurlan et al., 1988) and the oral route exhibits considerable variation in both the rate and extent of absorption. If oral L-DOPA was used at a lower concentration, the range of dyskinesia severity might vary greatly within a group of 6-OHDA-lesioned animals, which would compromise the evaluation of LID.

The daily dose of L-DOPA (Prolopa dispersive, Hoffman-LaRoche, Brazil) was $20 \mathrm{mg} \mathrm{kg}-1$ plus a peripheral decarboxylase inhibitor, benserazide (5 $\mathrm{mg} \mathrm{kg}-1$ ) (orally by gavage, dissolved in water). Doxycycline (40 $\mathrm{mg}$ kg-1, intraperitoneal [i.p.], Sigma) and COL-3 (i.c.v.) were dissolved in saline, since to ensure high lipid solubility with good penetration of the blood-brain barrier (Andersson and Alestig, 1976; Barza et al., 1975; Klein and Cunha, 1995; Liu et al., 2001).

L-DOPA-primed rats due to chronic L-DOPA treatment (14 days) were administered doxycycline or COL-3 after dyskinesia was present. The groups of parkinsonian rats submitted to doxycycline+L-DOPA (14 days, chronic) had not received treatment with L-DOPA previously. Doxycycline (i.p.) was administered 30 min before the L-DOPA or vehicle (gavage) in all experiments. Acute COL-3 (i.c.v.) was administered $10 \mathrm{~min}$ before the L-DOPA or vehicle.

\section{Abnormal involuntary movements (AIMs)}

Two weeks after the 6-OHDA microinjection rats received a daily oral administration of L-DOPA for 14 days. The AIMs score was assessed by an experienced observer that was blinded to the treatment, according to a scale described by Anderson et al., (1999), Cenci and Lundblat, (2007) and modified by Padovan-Neto et al. (2009). The sum of the severity+amplitude score of the axial, limb, and orofacial AIMs for each monitored period is referred to as the global AIMs score or ALO AIMs (Anderson et al., 1999). AIMs were scored over a 1-min period every $20 \mathrm{~min}$ for a total of $180 \mathrm{~min}$, post-L-DOPA administration. Each of the three subtypes was scored according to the severity scale, which ranges from 0 to 4 (where $0=$ absent, $1=$ occasional, $2=$ frequent, $3=$ continuous but interrupted by sensory distraction, and $4=$ continuous, severe and not suppressible). In addition, the amplitude of the ALO AIMs, and L-DOPA induced AIMs score, was measured and ranged from 0 to 4 (the maximum amplitude of the L-DOPA induced AIMs score during the observation period. A dyskinesia time curve was generated by plotting the L-DOPA induced AIMs score against each monitoring time $(20,40,60,80,100,120,140,160$, and $180 \mathrm{~min})$ for an entire testing session. We have created individual curves for each L-DOPA induced AIMs score category (limb, orofacial, and axial). Based on previous studies (Lundblad et al., 2002; Winkler et al., 2002), animals with an L-DOPA induced AIMs score of $>10$ and severity grading of $>2$ on at least one L-DOPA induced AIMs score subtype during treatment with L-DOPA, were selected for the behavioral analysis.

\section{Motor activity tests}

To control for any effects of doxycycline on motor activity and motor deficits following 6-OHDA+L-DOPA 
treatment, the forepaw adjusting steps test and the open field test were performed. Vehicle or doxycycline was injected 30 minutes before L-DOPA.

Forepaw adjusting steps test: The stepping test has been used as a measure of forelimb akinesia, demonstrating sensitivity to dopamine loss as well as the reversal of the deficit by dopamine replacement therapy (Chang et al., 1999; Olsson et al., 1995). Briefly, the experimenter restrained the rat, so that the hind limbs were lifted, and one front paw was free for weight-bearing. The rats were dragged laterally across a table $(90 \mathrm{~cm} / 10 \mathrm{~s})$, and a trained rater blind to the condition counted the steps. Three trials were conducted for each forepaw and included both forward and backward stepping. Each forepaw was alternated, with the forepaw that was contralateral to the lesion tested first. Baseline stepping measurements were obtained before initiation of the study (pre-test), and $60 \mathrm{~min}$ after L-DOPA treatment on days 1, 7, and 14. The results are presented as a percentage of the number of forehand adjusting steps taken with the intact paw relative to the total number of adjusted steps.

Open field test: The rats' spontaneous activity in the open field was tested 60 min after L-DOPA or vehicle administration. Each rat was individually placed in the center of the arena and allowed to explore the open field for $5 \mathrm{~min}$. The behavior recognition system (ANY-maze 4.9, Stoelting USA) was used to calculate the distance traveled and time of immobility.

\section{Tissue collection and processing}

Rats were anesthetized with tribromoethanol (1.5 g kg-1, Sigma-Aldrich, St. Louis, MO, USA) 60 min after the last L-DOPA injection before being sacrificed.

Tissue collection for immunohistochemistry: Anesthetized rats were perfused transcardially with $100 \mathrm{~mL}$ of Kreb's-ringer buffer and $200 \mathrm{~mL}$ of buffered picric acid-paraformaldehyde fixative room temperature (Somogyi and Takagi, 1982: one liter of fixative was made up by mixing in the following order: $500 \mathrm{ml}$ of $0.2 \mathrm{M}$

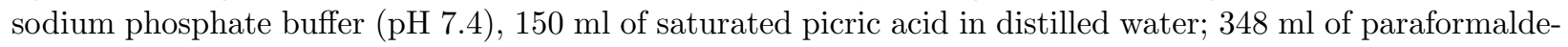
hyde solution containing $40 \mathrm{~g}$ of depolymerized paraformaldehyde and $2 \mathrm{ml}$ of $25 \%$ glutaraldehyde). The final $\mathrm{pH}$ was between 7.2 and 7.4 , and the final concentrations were $4.0 \%$ paraformaldehyde, $0.05 \%$ glutaraldehyde, and $0.2 \%$ picric acid.

After perfusion, the brain was removed from the skull and fixed by immersion in the same fixative for 60 min at $4{ }^{\circ} \mathrm{C}$. Then, it was cryoprotected in a $30 \%$ sucrose solution in $0.1 \mathrm{M}$ phosphate buffer for $24 \mathrm{~h}$. The brains were quickly frozen in isopentane cooled in liquid nitrogen $\left(-40{ }^{\circ} \mathrm{C}\right.$, Sigma-Aldrich, St. Louis, MO, USA) and stored at $-80 \mathrm{degC}$ until histological processing. Serial coronal sections $(25 \mu \mathrm{m})$ were cut using a freezing microtome (Leica, model CM1850) throughout the rostrocaudal extent of the striatum and the SNc (Paxinos \& Watson, 2004). The sections were collected in an anti-freeze solution (50\% phosphate buffer, $0.05 \mathrm{M} \mathrm{pH} 7.3,30 \%$ ethylene glycol, $20 \%$ glycerol) for preservation and subsequent processing.

Immunohistochemical reaction: Immunostaining was performed on free-floating sections with standard avidin-biotin protocols (Bortolanza et al., 2015 a, b; Gomes et al. 2008) with the antisera presented in Supplementary Table 1.

Free-floating sections were submitted to antigen recovery by heating for $30 \mathrm{~min}$ in a water-bath at $60{ }^{*} \mathrm{C}$ in $0.1 \mathrm{M}$ citrate buffer with a $\mathrm{pH}$ of 6.0. After rinsing in the washing buffer (phosphate-buffered saline 0.1 M (PBS - sodium chloride $\mathrm{NaCl}$, (mw: $58.4 \mathrm{~g} / \mathrm{mol}$ ); potassium chloride $\mathrm{KCl}$ (mw: $74.551 \mathrm{~g} / \mathrm{mol}$ ); sodium hydrogen phosphate Na2HPO4 (mw: $141.96 \mathrm{~g} / \mathrm{mol}$ ); monopotassium phosphate KH2PO4 (mw: 136.086 $\mathrm{g} / \mathrm{mol}))+0.15 \%$ Triton-X100; $\mathrm{pH} 7.4$ ), the sections were incubated for $30 \mathrm{~min}$ with $1 \%$ hydrogen peroxide (diluted in washing buffer) to block endogenous peroxidase activity. Nonspecific binding sites were blocked by incubation in a solution containing $2 \%$ bovine serum albumin plus $5 \%$ normal serum (from the species of origin of the secondary antibody) in washing buffer for 60 min. Next, the sections were incubated with primary antibody against tyrosine hydroxylase (TH), FosB, glial fibrillary acidic protein (GFAP to reveal astrocytes), OX-42 (CD11b/c equivalent protein of microglia to reveal microglia) or cyclooxygenase2 enzyme-labeled cells (COX-2). After incubation in the primary antibody for $24 \mathrm{~h}$, the sections were 
successively rinsed in the washing buffer and incubated in biotinylated secondary antibody solution (in PBS) for 90 min (Supplementary Table 1). Sections were then incubated with the avidin-biotin-peroxidase complex for $2 \mathrm{~h}$ (Vectastain ABC kit, Vector Lab, Burlingame, CA, USA), and the immunoreactivity was revealed by a peroxidase reaction using 3,3'-Diaminobenzidine diaminobenzidine (DAB; Sigma) as the chromogen.

Quantification analysis: All analyses were done in the dorsal striatum by an experimentally blind investigator. The quantification of FosB, COX-2, astrocytes, microglia were carried out as in previous studies (Bortolanza et al., 2015 a, b; Padovan et al., 2015). Digital images were obtained using a Leica microscope (Leica Microsystems Launches Leica FW4000 - Cambridge, UK) under 20x or 40x objectives. The quantification of the brain area was measured using the ImageJ system (National Institutes of Health - NIH; Schneider et al., 2012).

Analysis of microglia (OX-42) and astrocyte (GFAP) immune labeling morphology was conducted as described by Giocanti-Auregan et al. (2016) using Fiji algorithms and a generated skeleton image. The parameters analyzed were the number of branches, the number of intersections or branching points, and the mean process length.

For FosB, COX-2, GFAP, and OX-42, the results were expressed as the number of cells per $0.5 \mathrm{~mm}^{2}$. For GFAP and OX-42, the results were also expressed as the number of branches of intersections of branching points and process length per $\mathrm{mm}^{2}$ or length per $\mathrm{mm}^{2}$.

Tissue collection for in situ fluorogenic reaction and gel electrophoresis An independent experimental group of rats was used to assess the in situ gelatinolytic activity and ROS concentration, and another group for the substrate gel electrophoresis of metalloproteinases and western blotting (see experimental design). At the end of the behavioral analyzes, animals were anesthetized as described in the tissue collection and processingsection, immediately decapitated, and the brain removed.

To assess the in situ gelatinolytic activity of MMPs and ROS presence, each brain was embedded in Tissuetek@, quickly frozen in isopentane (-40 degC, Sigma-Aldrich, St. Louis, MO, USA) and stored at $-80 \operatorname{degC}$ until histological processing. Coronal sections $(5 \mu \mathrm{m})$ of the striatum were cut using a freezing microtome (Leica, model CM1850).

To assess MMP-2 and MMP-9 presence by substrate gel zymography and the MMP-3 protein concentration by western blot, the rat brain was removed and dissected. The dorsal striata were micro-dissected on an ice-cooled plate and immediately frozen in dry ice.

A block of tissue containing the SNc prevenient from the above described experimental animal brain was post-fixed in buffered picric acid-paraformaldehyde fixative for $6 \mathrm{~h}$ at $4{ }^{\circ} \mathrm{C}$ for TH-immunoreactivity analysis (see immunohistochemistry). The SNc blocks were quickly frozen in isopentane (-40 degC) and stored at -80 degC. The brain sections were collected and processed, as described in theimmunohistochemistry section.

Gelatinolytic zymography in situ: Zymography is a technique that can be used for the detection of hydrolytic enzymes based on the substrate repertoire of the enzyme. This technique allows for the precise localization of the two MMPs identified as active gelatin-degrading enzymes (gelatinases), i.e., gelatinase A (72-kDa MMP-2) and gelatinase B (92-kDa MMP-9), in the gently fixed tissue section (Galis et al., 1995; Lee et al. 2004; Nascimento et al. 2013). A dye-quenched (DQ)-gelatin degradation assay to quantify MMP-2/MMP-9 activities was performed in the striatum tissue samples by zymography.In situ MMP activity was measured in $5 \mu \mathrm{m}$ sections using DQ-Gelatin (E12055, Molecular Probes, USA) as a fluorogenic substrate. The gelatin with a fluorescent tag remains caged (no fluorescence) until the gelatin is cleaved by MMPs 2/MMP-9. Sample sections were incubated with $1.0 \mathrm{mg} \mathrm{mL}^{-1}$ of DQ-Gelatin in Tris-CaCl2 buffer $(50 \mathrm{mM}$ Tris, $10 \mathrm{mM}$ $177 \mathrm{CaCl} 2,1 \mathrm{mM} \mathrm{ZnCl2}$ ) in dark and humidified chambers for $60 \mathrm{~min}$. Proteolytic activity was detected as bright green fluorescence, which indicated substrate breakdown. Arbitrary fluorescence units were evaluated using Image (NIH, USA). Negative control sections were incubated in the same way as described above but without DQ gelatin.

In situ reactive oxygen species measurement (ROS) In situvisualization of ROS production allows for the 
precise localization of ROS in specific brain regions. The reaction was performed using dihydroethidium [DHE, Sigma Chemical Co. (St. Louis, MO, USA)]. DHE exhibits red fluorescence through interactions with superoxide and other free radicals in the brain (Castro et al. 2009). Briefly, in situROS quantification was measured in sections 5 - $\mu \mathrm{m}$ thick of the striatum (obtained as described above for in situ gelatinolytic zymography) incubated with DHE (10 $\mathrm{mol} \mathrm{L}^{-1}$; Castro et al., 2009; Fernández et al. 2018) in dark wet chambers, at room temperature, for $30 \mathrm{~min}$. They were post-fixed in $4 \%$ paraformaldehyde in $0.1 \mathrm{M}$ phosphate buffer for $10 \mathrm{~min}$ and then examined by fluorescence microscopy (Leica Microsystems Launches Leica FW4000 - Cambridge, UK). Bright red fluorescence represented ROS (arbitrary fluorescence units) and was evaluated using ImageJ (NIH, USA). Negative control sections were incubated in the same way as described above but without DHE.

Substrate gel electrophoresis for MMP-2 and MMP-9 and western blot for MMP-3 Frozen striatum samples were homogenized in $300 \mathrm{~mL}$ extraction buffer that consisted of $10 \mathrm{mM}$ of $\mathrm{CaCl}_{2}, 50 \mathrm{mM}$ of Tris-HCl, 1 $\mathrm{mM}$ of 1, 10 ortho-phenanthroline, phenylmethylsulphonyl fluoride (PMSF, a serine protease inhibitor) at $100 \mu \mathrm{M}$ and $1 \mathrm{mM}$ of N-ethylmaleimide to extract the proteins. Lesioned and non-lesioned dorsal striata were processed separately. After $20 \mathrm{~h}$ at $4^{\circ} \mathrm{C}$, the samples were centrifuged at $3000 \mathrm{~g}$ for $15 \mathrm{~min}$, and the protein content was measured using the Bradford (1976) method. The samples were then diluted in the sample buffer (2\% SDS, $125 \mathrm{mM}$ Tris- $\mathrm{HCl} \mathrm{pH} \mathrm{6.8,10 \%} \mathrm{glycerol,} \mathrm{and} 0.001 \%$ bromophenol blue) and subjected to electrophoresis on 12\% SDS-PAGE co-polymerized with $1 \%$ gelatin (Sigma Chemical Co. St. Louis, MO, USA) as the substrate. After electrophoresis was completed, the gel was incubated in a $2 \%$ Triton X-100 solution followed by Tris- $\mathrm{HCl}$ buffer $\mathrm{pH} 7.4+10 \mathrm{mM} \mathrm{CaCl} 2$. The gels were stained with $0.05 \%$ coomassie brilliant blue. The gelatinolytic activity was detected as unstained bands against the background of coomassie blue-stained gelatin. Metalloproteinases MMP-9 and MMP-2 protein in the striatum was detected as transparent bands against a dark-blue background (Nascimento et al., 2013). Enzyme activity was determined by densitometry using a Kodak Electrophoresis Documentation and Analysis System (EDAS 290; Kodak, USA).

To analyze the antibody specificity by western immunoblotting, and to quantify striatal MMP-3-related protein expression, total protein extracts were obtained from the dorsal striatum, which was homogenized in buffer containing $137 \mathrm{mM}$ of NaCl, $20 \mathrm{mM}$ of Tris, $\mathrm{pH}$ of 8.0, $1 \%$ NP- 40, $0.105 \%$ SDS, $10 \%$ glycerol, and protease inhibitors $0.2 \mathrm{mM}$ of phenylmethylsulphonyl fluoride (PMSF), $0.1 \mu \mathrm{M}$ of aprotinin and $1 \mu \mathrm{M}$ of leupeptin (N-acetyl-L-leucyl-L-leucyl-L-argininal) and phosphatase inhibitors $(1 \mathrm{mM}$ of NaF and $2 \mathrm{mM}$ of $\mathrm{Na}_{3} \mathrm{VO}_{4}$ ). After homogenization, the sample was centrifuged $\left(13,000 \mathrm{~g}\right.$ at $4{ }^{\circ} \mathrm{C}$ for $\left.20 \mathrm{~min}\right)$. The supernatant and the precipitate were separated, and the total amount of protein in the supernatant was determined by the Bradford (1976) method. Samples containing $0.5 \mathrm{mg}$ of protein were separated by polyacrylamide gel electrophoresis containing 12\% SDS-PAGE and electrically transferred to a polyvinylidene difluoride (PVDF) membrane (Millipore, MA, USA). Detection of the proteins on the membrane was done by sequential incubations with the primary and secondary antibodies (see Table S1) and evaluated using the ImmobilonTM Western Chemiluminescent HRP Substrate detection system (Millipore) and registered by ImageQuant 350 detection system (GE Healthcare).

\section{Experimental Design}

After surgery, all rats were allowed to recover for two weeks. L-DOPA or vehicle treatment started two days after the apomorphine rotational test. Animals were assigned randomly to experimental groups that were well-matched regarding the rotational rate (results not shown). Each experimental group was daily treated with L-DOPA $\left(20 \mathrm{mg} \mathrm{kg}^{-1}\right)$ plus benserazide- $\mathrm{HCl}\left(5 \mathrm{mg} \mathrm{kg}^{-1}\right)$ or saline by gavage once a day for 15 days. The study consisted of four different main experiments.

Experiment 1- Impact of acute administration of doxycycline on LID expression once dyskinesia was present

In this experiment, group 6-OHDA+vehicle+L-DOPA $(\mathrm{n}=11)$ treated animals received L-DOPA for 14 days. On day $15,50 \%$ of the animals received acute doxycycline (40 $\mathrm{mg} \mathrm{kg}^{-1}$, i.p., once), $30 \mathrm{~min}$ before L-DOPA 
(6-OHDA+doxycycline+L-DOPA, $\mathrm{n}=6$ ). The other parkinsonian animals received vehicle before L-DOPA (6OHDA+vehicle+L-DOPA, $\mathrm{n}=5$ ). After 3 days of drug washout, the allocation of the animals to "drug" versus "vehicle" treatment was switched. Therefore, each animal was submitted to both treatments. A comparison between the AIMs scores among the 6-OHDA+doxycycline+L-DOPA and 6-OHDA+vehicle+LDOPA groups was performed using a one-way repeated measures analysis of variance (ANOVA-RM).

An additional group of parkinsonian animals received similar treatment to those described above underwent the motor activity tests, the forepaw adjusting step, and the open field test. Experimental groups were composed of animals with already established LID: 6-OHDA+vehicle+L-DOPA $(\mathrm{n}=11)$ and 6-OHDA+doxycycline+L-DOPA $(\mathrm{n}=11)$. Comparisons of the AIMs scores between the experimental groups were performed by one-way ANOVA, followed by Bonferroni's multiple comparisons test. The control groups were no-lesion+vehicle+vehicle $(\mathrm{n}=6) ; 6$-OHDA+vehicle+vehicle, $(\mathrm{n}=8) ; 6$-OHDA+doxycycline+ vehicle $(\mathrm{n}=9)$.

\section{Experiment 2- Effect of chronic doxycycline on the development of LID}

To extend these novel findings, we also examined whether chronic, doxycycline administration would attenuate the development of LID. We examined whether the co-treatment of doxycycline (40 mg $\mathrm{kg}^{-1}$, i.p., once a day, 15 days) to lesioned rats, $30 \mathrm{~min}$ before L-DOPA, influenced the development of LID. The experimental groups consisted of $6-\mathrm{OHDA}+$ chronic-vehicle+L-DOPA $(\mathrm{n}=11)$ and 6 OHDA+chronic-doxycycline+L-DOPA $(n=11)$. There was no AIMs manifestation in the control group animals [no-lesion+chronic-vehicle+vehicle $(\mathrm{n}=6) ; 6$-OHDA+chronic-vehicle+vehicle $(\mathrm{n}=6) ; 6$-OHDA+chronicdoxycycline+vehicle $(n=7)]$. Individually all animals were submitted to the open field test one hour after L-DOPA treatment to evaluate their motor behavior. Comparisons of the scores between the experimental groups were performed by two-way ANOVA-RM, followed by Bonferroni's multiple comparisons test.

Experiment 3- Striatal LID markers expression after administration of doxycycline

In this experiment, the immunoreactivity of FOS-B (a canonical protein associated with LID), proteins typical of neuroinflammation such as COX-2, GFAP, OX-42, MMPs, and the presence of ROS were evaluated. The experimental groups comprised parkinsonian rats with already established LID that were receiving acute doxycycline treatment and parkinsonian rats receiving doxycycline treatment since day one as well as the respective controls. An individual experimental group assembly was prepared for each analysis described below.

Experiment 3.1. Striatal LID markers expression in rats acutely treated with doxycycline once dyskinesia was present

(i) Immunohistochemical reaction for COX-2, GFAP, OX-42 in the experimental groups: 6OHDA+vehicle+L-DOPA, $(\mathrm{n}=7) ; 6$-OHDA+doxycycline+L-DOPA $(\mathrm{n}=8)$ and the respective controls $[$ nolesion+vehicle+vehicle; $(\mathrm{n}=6), 6$-OHDA+vehicle+vehicle $(\mathrm{n}=5), 6-$ OHDA+doxycycline+vehicle $(\mathrm{n}=5)]$.

(ii) MMP-3 immunoblotting, MMP-2 and MMP-9 gel zymography in the striatum of the experimental groups: 6-OHDA+vehicle+L-DOPA $(\mathrm{n}=7), 6$-OHDA+doxycycline+L-DOPA $(\mathrm{n}=6)$, and the respective controls [nolesion+vehicle+vehicle $(\mathrm{n}=6), 6-\mathrm{OHDA}+$ vehicle+vehicle, $(\mathrm{n}=6), 6-\mathrm{OHDA}+\mathrm{DOX}+$ vehicle $(\mathrm{n}=6)]$.

(iii) MMP-2/-9 in situ gelatinolytic zymography and ROS histochemistry analysis in the brain sections of the experimental groups: 6-OHDA+vehicle+L-DOPA $(\mathrm{n}=7), 6-\mathrm{OHDA}+$ doxycycline+L-DOPA $(\mathrm{n}=7)$, and the respective controls [no-lesion+vehicle+vehicle $(\mathrm{n}=6), 6$-OHDA+vehicle+vehicle $(\mathrm{n}=6), 6$ OHDA+doxycycline+vehicle $(\mathrm{n}=6)]$.

Experiment 3.2. Striatal ROS and MMP expression in rats chronically treated with doxycycline $+L-D O P A$

(i) MMP-2/MMP-9 in situ gelatinolytic zymography and ROS histochemistry was measured at the striatum slices of the experimental groups: 6-OHDA+chronic-vehicle+L-DOPA $(n=7), 6$-OHDA+chronicdoxycycline+L-DOPA $(\mathrm{n}=8)$ and the respective controls [no-lesion+chronic-vehicle+vehicle $(\mathrm{n}=6), 6$ OHDA+chronic-vehicle+vehicle $(\mathrm{n}=6), 6-\mathrm{OHDA}+$ chronic-doxycycline+vehicle $(\mathrm{n}=6)]$. 
(ii) MMP-2 and MMP-9 substrate gel zymography was measured at the striatum tissue in the experimental groups: 6-OHDA+chronic-vehicle+L-DOPA $(\mathrm{n}=7), 6-\mathrm{OHDA}+$ chronic-doxycycline+L-DOPA $(\mathrm{n}=6)$ and the respective controls [no-lesion+chronic-vehicle+vehicle $(\mathrm{n}=6), 6$-OHDA+chronic-vehicle+vehicle $(\mathrm{n}=6), 6$ OHDA+chronic-doxycycline+vehicle $(\mathrm{n}=6)]$.

Experiment 4 Impact of acute administration of COL-3 on LID expression once dyskinesia was present

In this experiment, a group of 6-OHDA+vehicle+L-DOPA $(\mathrm{n}=15)$ animals received L-DOPA for 14 days. To test the COL-3 effect (50 and $100 \mathrm{nmol}$ - approximately 0.1 and $0.2 \mu \mathrm{g} \mathrm{kg-1;} \mathrm{Echelon} \mathrm{Biosciences,} \mathrm{Salt}$ Lake, UT, USA, dissolved in saline), after L-DOPA treatment rats had an i.c.v. cannula (15-mm guide cannula, 22 gauge, C313/G/SPC; Plastics One Inc., Roanoke, VA) implanted above the left lateral ventricle (AP: $+0.4 \mathrm{~mm}$, ML: $-2.9 \mathrm{~mm}$, DV: $-4.0 \mathrm{~mm}$ relative to bregma (see the dopaminergic neuronal lesion with 6-OHDA section for details of the surgery). The cannula was stabilized with 5 micro screws and fixed with Jet Denture Repair Acrylic (Lang Dental, Wheeling, IL). The guide cannula was fitted with a 28 -gauge inner stylet (Plastics One) to maintain cannula patency. The animals were allowed to recover for five to seven days.

Animals were administered COL-3 (50 and $100 \mathrm{nmol}, \mathrm{n}=7)$. The drug and the vehicle were injected into the ventricle of awake animals through a 15-mm-length stainless steel needle attached to an infusion pump 10 minutes before L-DOPA. To ensure that the investigator was blind to the rats' individual treatment, COL-3 or vehicle was given randomly on either day 1 or day 2 of a 2 consecutive days testing period. On day 1 , the animals received acute COL-3 $(\mathrm{n}=8)$, of either 50 or $100 \mathrm{nmol}$. The other animals $(\mathrm{n}=7)$ received vehicle before L-DOPA. A comparison between the AIMs scores among 6-OHDA+COL-3+L-DOPA vs. 6-OHDA+vehicle+L-DOPA was performed by one-way ANOVA-RM, followed by Bonferroni's test.

The animals had their motor activity evaluated using the open field test, one hour after L-DOPA application.

Cannula placement was analyzed through striatal sections mounted on gelatinized slides using a light microscope (Leica Microsystems Launches Leica FW4000 - Cambridge, UK) following cresyl violet staining (Sigma-Aldrich). All the tested animals had the cannula inserted in the lateral ventricle, between AP-3.4 to $-4.3 \mathrm{~mm}$.

\section{Statistical Analyses}

Cenci and Lundblat (2007) indicated that AIM scores should be treated parametrically because the basic scores for LID reflect the proportion of time during which a given behavioral manifestation is present. Also, it has been shown that AIM scores are linearly and closely correlated with parametric quantities (Cenci and Lundblat, 2007).

All statistical analyses were conducted using GraphPad Prism software 6. A p-value of $<.05$ was considered statistically significant.

The acute administration of doxycycline or COL-3 and vehicle on L-DOPA-induced AIMs scores, and the open field and forepaw adjusting step tests were compared by one-way ANOVA followed by Bonferroni's test. Data are presented as the mean \pm SEM with points representing data from individual animals.

A comparison of the chronic administration of doxycycline and vehicle combined with L-DOPA was performed by two-way RM-ANOVA followed by Bonferroni's test. To analyze the immunohistochemical and fluorescence intensity results, a one- or two-way ANOVA was performed to determine the difference between factors L-DOPA (6-OHDA+vehicle+L-DOPA and doxycycline (6-OHDA+doxycycline+L-DOPA) followed by Bonferroni's test to determine the statistical difference. For the western blotting analysis, the Students t-test was used to compare the expression of markers in the 6-OHDA+vehicle+L-DOPA vs. 6-OHDA+doxycycline+LDOPA treated animals. Correlations were estimated using simple regression analyses. Figure legends indicate the test used for each experiment. The data are presented as the mean +- SEM.

\section{RESULTS (1330 words)}




\section{Analysis of the 6-OHDA-lesion}

$\mathrm{TH}$ immunostaining in the striatum and the SNc was used to evaluate the degree of the dopaminergic lesion. There was a marked reduction of the dopaminergic neurons in the SNc and TH-positive fibers in the lesioned striata (Supplementary Fig. 1) compared to the no-lesioned rat striata. There was no difference in the extent of the lesion between the animals in each group.

\section{Impact of acute administration of doxycycline on LID expression once dyskinesia was present}

During the chronic L-DOPA treatment, $90 \%$ of the rats developed AIMs affecting the contralateral forelimb and orofacial structures, together with trunk dystonia (Fig. 1-A, p<0.05, 6-OHDA+vehicle+L-DOPA). The maximum total AIMs score (ALO-AIMs Fig. 1-A) was reached 40-80 min after L-DOPA administration and gradually declined to the baseline level over $180 \mathrm{~min}$ (Fig. 1-B). Administration of doxycycline (40 mg kg-1), 30 min before L-DOPA significantly reduced AIMs (89\%; Fig. 1-A, 6-OHDA+vehicle+L-DOPA ALO AIMs score $=92.22+-8.66$ vs. 6 -OHDA+doxycyclineL-DOPA ALO AIMs score $=10.56+-4.89, \mathrm{p}<0.0001)$ over 20 to 120 min observation period (Fig. 1-B). Acute doxycycline before L-DOPA also decreased the individual AIM categories (axial, forelimb, and orofacial; Supplementary Fig. 2). AIM was not observed in both the non-lesioned rats and lesioned rats treated with vehicle or doxycycline (data not shown).

Doxycycline does not affect the therapeutic effect of $L-D O P A$

The lesioned animals displayed akinesia of the contralateral forelimb (Fig. 1-C, stepping test) and a decrease in the distance traveled (Fig. 1-D, open-field test) demonstrating compromised motor ability. L-DOPA treatment improved akinesia and increased the distance traveled (Figs. 1-C and -D). Doxycycline did not improve motor function as revealed by the akinesia (Fig. 1-C, stepping test) and distance traveled (Fig. 1-D, open-field test).

Impact of the acute administration of doxycycline on LID associated markers once dyskinesia was present

Expression of FosB: Similar to described by Padovan-Neto et al., (2009) and others, FosB protein expression increased in the cell nuclei in the lesioned striatum of parkinsonian rats receiving L-DOPA (6OHDA+vehicle+L-DOPA; Figs. 2-A, -B, -C). The acute administration of doxycycline caused a significant decrease in the expression of FosB (40\%; 6-OHDA+doxycycline+L-DOPA; $\mathrm{p}<0.001$; Fig. 2-C).

Expression of COX-2: Similar to described by Bortolanza et al., (2015b), L-DOPA increased the number of cells expressing COX-2 (6-OHDA+vehicle+L-DOPA; Figs. 2-D, -E, -F) in the dopamine-depleted striatum. Doxycycline significantly reduced the induction of LID associated COX-2 (6-OHDA+doxycycline+L-DOPA; $\mathrm{p}<0.05$; Figs. 2-E and $-\mathrm{F}$ ).

Expression of GFAP and OX42: We investigated how L-DOPA, alone or combined with acute doxycycline, would affect the number (Figs. 2-G, -H, -I, -J, -K and -L) and morphology (Supplementary Fig. 3) of the astrocytes and microglia using GFAP and OX42 immunohistochemical labeling, respectively. The number of astrocytes increased as did the number activated in the dopamine-depleted striatum. It was showed an increased GFAP-immunoreactivity (6-OHDA+vehicle+L-DOPA; Figs. 2-G and -I) and cellular hypertrophy (6-OHDA+vehicle+L-DOPA; Supplementary Figs. 3-A, -B and -C). Also, L-DOPA treatment increased the number of microglia as characterized by increased OX-42 density (6-OHDA+vehicle+L-DOPA; Figs. 2-J and $-\mathrm{L}$ ) and hypertrophic morphology (6-OHDA+vehicle+L-DOPA; Supplementary Figs. 3-D, -E and -F). Doxycycline administered before L-DOPA reduced each of these L-DOPA treatment-induced changes in the depleted striatum (6-OHDA+doxycycline+L-DOPA; Figs. 2-H, -I, -K and -L; Supplementary Fig. 3).

The increase of the immunoreactivity of Fos-B, COX2, GFAP, OX-42 in LID, or evidence of microglia and astrocytes activation was not observed in the striatum of non-lesioned rats and lesioned rats treated with only vehicle or doxycycline (data not shown).

Impact of the acute administration of doxycycline on LID induced ROS and MMPs once dyskinesia was present 
ROS detectio n: The levels of red fluorescence of dihydroethidium (DHE) oxidation as an indicator of ROS levels increased in the lesioned striatum of parkinsonian animals treated with L-DOPA (6-OHDA+vehicle+LDOPA; Figs. 3-B, -G, arbitrary units). Acute doxycycline treatment prior to L-DOPA led to a slight but significant decrease in DHE oxidation (6-OHDA+doxycycline+L-DOPA; Figs. 3-C, -G; p < 0.05). The increased level of ROS had no significant correlation with dyskinesia severity (Fig. 3-H).

Detection of MMP-2/MMP-9 activity: A fluorescein isothiocyanate (FITC) signal representing MMP2/MMP-9 activity was observed in the striatum of lesioned rats (6-OHDA+vehicle+vehicle; Figs. 3-D and -I) and the striatum of rats expressing L-DOPA induced dyskinesia (6-OHDA+vehicle+LDOPA; Figs. 3 -E and -I). Doxycycline acute treatment significantly reduced the MMP-2/-9 activity (Figs. 3-F and -I). MMP-2/MMP-9 activity was highly correlated with dyskinesia severity $(\mathrm{r}=0.9 ; \mathrm{p}<0.01$; Fig. 3-J).

MMP-2 and MMP-9 gel zymography: The presence of the MMP-2 (72 kDa) and the MMP-9 (97 kDa) was detected by substrate gel zymography in the lesioned striatum (Supplementary Fig. 4). Striatal MMP-2 patterns did not change wither following lesion (6-OHDA+vehicle+vehicle), or L-DOPA treatment alone (6-OHDA+vehicle+L-DOPA) or with acute doxycycline (6-OHDA+doxycycline+L-DOPA) (Supplementary Fig. 4-A). Contrastingly, the striatal MMP-9 signal was increased after 6-OHDA-lesion but not modified by L-DOPA treatment. Interestingly, acute doxycycline treatment significantly reduced MMP-9 in lesioned rats but reached statistical significance after L-DOPA treatment ( $<<0.05$; Supplementary, Fig. 4-B).

MMP-3 protein level: The western blot analysis revealed an increased amount of MMP-3 in the lesionedstriatum of dyskinetic rats (6-OHDA+vehicle+L-DOPA), which was significantly reduced by doxycycline administration (6-OHDA+doxycycline+L-DOPA; $<<0.0001$; Fig. 3-K). The increase in MMP-3 levels was positively correlated with dyskinesia severity $(\mathrm{r}=0.9 ; \mathrm{p}<0.01$, Fig. $3-\mathrm{L})$.

\section{Effects of chronic doxycycline on the development of LID}

L-DOPA induced the appearance of dyskinesia in the parkinsonian rats (6-OHDA+chronic-vehicle+L-DOPA; Fig. 4-A). Co-administration of doxycycline with L-DOPA (6-OHDA+chronic-doxycycline+L-DOPA decreased the AIMs measured at days 1,7 , and 14 of the combined treatment $(\mathrm{p}<0.0001$; Fig. 4-A). Post hoc analyses revealed a significant reduction of the total AIMs (Fig. 4-A) and the different AIMs types (Supplementary Figs. 2-D, -E and -F; p<0.05, 6-OHDA+chronic-vehicle+L-DOPA vs. 6-OHDA+chronicdoxycycline+L-DOPA). AIMs were not observed in the control group or the 6-OHDA-lesioned rats that were treated with vehicle or doxycycline only (data not shown).

The lesioned animals showed a decrease in the distance traveled, as evaluated by the open-field test (6OHDA+chronic-vehicle+vehicle; Supplementary Table 1), demonstrating compromised motor ability. LDOPA treatment increased the distance traveled (6-OHDA+chronic-vehicle+L-DOPA Supplementary Table 1 ), and the co-administration of L-DOPA+doxycycline did not affect the improvement in locomotor activity (6-OHDA+chronic-doxycycline+L-DOPA $\mathrm{p}<0.05$; Supplementary Table 1).

Impact of the chronic administration of doxycycline on LID induced ROS and MMPs

Reactive oxygen species: 6-OHDA lesion and L-DOPA treatment increased ROS production as measured by fluorescence intensity (Figs. 4-D and -I) in the dopamine-denervated striatum. Co-administration of doxycycline (6-OHDA+chronic-doxycycline+L-DOPA) reduced the ROS fluorescence intensity (80\% arbitrary units) (Figs. 4-E and -I). The ROS level was positively correlated with the dyskinesia severity $(\mathrm{r}=0.9$; $\mathrm{p}<0.0001$; Fig. 4-J).

Expression of MMP-2/MMP-9 activity : The activity of MMP-2/MMP-9 increased in the striatum of rats with 6-OHDA lesions (6-OHDA+chronic-vehicle+vehicle), and those with L-DOPA induced dyskinesia (6OHDA+chronic-vehicle+L-DOPA Figs. 4-F, $-\mathrm{G}$ and $-\mathrm{K}$ ). Doxycycline reduced MMP-2/MMP-9 activity in the 6-OHDA lesioned rats (6-OHDA+chronic-doxycycline+vehicle) and after L-DOPA induced dyskinesia (6-OHDA+chronic-doxycycline+L-DOPA $\mathrm{p}<0.0001$, Figs. $4-\mathrm{H}$ and $-\mathrm{K})$. The activity of MMP-2/MMP-9 exhibited a positive correlation with dyskinesia $(\mathrm{r}=0.7, \mathrm{p}<0.0001$, Fig. 4-L). 
MMP-2 and MMP-9 gel zymography: There was an increase in the MMP-2 and MMP-9 in the striatum of rats with 6-OHDA lesion (6-OHDA+chronic-vehicle+vehicle), without statistical significance. Doxycycline treatment per se slightly decreased MMP-2 and MMP-9 detection. The MMP-9 increase reached statistical significance following L-DOPA treatment $(6-\mathrm{OHDA}+$ chronic-vehicle $+\mathrm{L}-\mathrm{DOPA} ; \mathrm{p}<0.0001$, Supplementary Figs. 4-B and -D). Doxycycline co-treatment significantly reduced MMP-2 and MMP-9 detection after LID expression (6-OHDA+chronic-doxycycline+L-DOPA).

\section{COL-3 acute treatment attenuated LID once dyskinesia was present}

L-DOPA-treated lesioned rats were administered an i.c.v. microinjection of COL-3 at two different doses (50 or $100 \mathrm{nmol}, 10$ minutes before L-DOPA) over 10 days. A dose of $100 \mathrm{nmol}$ of COL-3 was found to significantly reduce L-DOPA induced dyskinesia (6-OHDA+vehicle+L-DOPA, AIMs sum 47.93+-7.93; lesion+COL-3+LDOPA, AIMs sum 20.57+-3.70; p < 0.01; Fig. 5-A; p <0.05). COL-3 reduced dyskinesia over a 20 to 140 min period, as observed in the time response curve (Fig. 5-B). No significant differences were found with $50 \mathrm{nmol}$ of COL-3 (6-OHDA+COL-3+L-DOPA: 42+-5.72). Moreover, COL-3 administration reduced axial, limb, and orofacial dyskinesia ( $<00.0001$; Supplementary Figs. 2-G, $-\mathrm{H}$ and $-\mathrm{I}$ ).

COL-3 treatment $(100 \mathrm{nmol})$ did not affect the L-DOPA improvements in the locomotor outcomes as measured by the distance traveled and time immobile (Supplementary, Table 1).

\section{DISCUSSION (1595 words)}

The acute administration of doxycycline or COL-3 demonstrated an anti-dyskinetic effect in rats with already established LID. Notably, we demonstrated that co-administration of doxycycline with L-DOPA since the first day of receiving L-DOPA suppressed the development of AIMs. Our results demonstrate that doxycycline or COL-3 are useful complements to L-DOPA, in that they block LID but maintain the improvements in motor function.

Doxycycline attenuated the increase in FosB, COX-2, GFAP, and OX42 expression in the lesioned striatum induced by L-DOPA treatment. The results demonstrated an increase in MMP-2/MMP-9 activity and ROS presence in the striatum of L-DOPA-dyskinetic parkinsonian rats. Treatment with doxycycline decreased MMP-2/MMP-9 activity and ROS induced by L-DOPA treatment. The increase of ROS and MMP-2/MMP9 activity was positively correlated with the degree of dyskinesia. Acute doxycycline treatment decreased MMP-9 gel detection related to LID, while chronic treatment decreased MMP2 and MMP-9 detection.

In agreement with our hypothesis, the modulation of inflammatory processes aimed at preventing or interrupting the cycle between damaged dopamine neurons, L-DOPA-treatment and dysregulated inflammation has the potential to emerge as a novel therapeutic strategy.

\section{Reduction of LID markers in the striatum of rats expressing LID after the acute administration} of doxycycline

FosB-expressing neurons appear in the brain of patients with PD (Lindgren et al., 2011; Tekumalla et al. 2001) and accumulation of FosB has been linked to the development of dyskinetic behavior in animal models (Anderson et al. 1999). Treatment with doxycycline decreased FosB up-regulation in the dopamine-depleted striatum of rats expressing LID.

Doxycycline treatment decreased COX-2 immunoreactivity in the dopamine-depleted striatum induced by L-DOPA treatment. Bortolanza et al., (2015b) and Berke et al. (1998) previously described the increase in COX-2 in the LID striata. COX-2 expression was also up-regulated in SNc dopaminergic neurons in both patients with PD and experimental PD models (Braak et al., 2008; de Meira Santos Lima et al., 2006; Knott et al., 2000; Teismann et al., 2003). The evidence for a direct role of COX-2 in PD and LID is still unclear (Bartels and Leenders, 2007).

In the striatum of parkinsonian rats presenting LID, it was found that GFAP and OX-42 immunoreactivity increased, along with the presence of reactive astrocytes and microglia, respectively (Bortolanza et al., 2015a, b; Lanza et al., 2019; Ramirez-Garcia et al., 2015). The pattern of neuroinflammatory-glial activation seen 
in our study was at least partially a consequence of the L-DOPA treatment in the lesioned animals. The glial activation identified was attenuated by treatment with doxycycline. Postmortem analyses of patients with PD have indicated the presence of reactive astrocytes and microglia (Ben Haim et al., 2015), which produce and release a variety of pro- and anti-inflammatory substances (Block et al., 2007; Liu et al., 2017; Rohl et al. 2007; Sidoryk-Wegrzynowicz et al., 2011; Wolf et al. 2017).

Taken together, FosB, COX-2, GFAP, and OX42 expression reduction as demonstrated by doxycycline treatment, is proposed to be part of a feasible therapeutic strategy for LID, and may well be appropriate for the treatment of PD patients.

\section{Positive correlation between striatal MMPs and ROS with overall LID severity}

The present study revealed an increase of ROS in the striatum of parkinsonian rats presenting LID. The neuroprotective effect of doxycycline has been attributed to its ability to scavenge ROS (Antonio et al., 2014). After chronic doxycycline treatment with L-DOPA, a robust correlation with ROS levels and LID intensity was established. Oxidative stress has been found to be one of the factors responsible for the initiation and progression of PD (Charvin et al., 2018; Zhou et al., 2008). An increase in MMPs may be a consequence of ROS production (Gottschall and Yu, 1995; Koli et al., 2008) and the presence of reactive astrocytes (Muir et al., 2002; Ogier et al., 2006). MMP-2/MMP-9 gelatinolytic activity and MMP-3 expression increased in the striatum of rats presenting L-DOPA dyskinesia. Alterations of MMP-2/MMP-9 activity and MMP3 expression were positively correlated with LID. Also, our results showed that MMP-2/MMP-9 activity and MMP-2 and MMP-9 gel detection also increase after 6-OHDA lesion. Doxycycline is an inhibitor of metalloproteinases activity (Bahrami et al., 2011; Garcia-Martinez et al. 2010; Nikodemova et al., 2006). The doxycycline treatment attenuated the MMP-2/MMP-9 activity increase when given either acutely or chronically to rats expressing LID. Contrastingly, the MMP-2 and MMP-9 gel detection was decreased, primarily after chronic treatment. We cannot explain the former contrasting results, but it is important to note that gel detection permits the separated detection of each enzyme and provides distinct in situ detection of the general gelatinases activities.

Lorenzl et al. (2004), Annese et al. (2015), and De Stefano and Herrero (2017) described the up-regulation of MMP-2/MMP-9 activity in neurons and microglia in the striatum and SNc in the MPTP model of PD. In the MPTP model, Chung et al. (2013) found increased MMP-3 protein and activity levels. In the postmortem brains of patients with PD, alpha-synuclein, and MMP-3 are co-localized in Lewy bodies (Choi et al. 2014, 2011). In contrast, Lorenzl et al. (2002) detected a 50\% reduction in MMP-2/MMP-9 activity levels in the SNc of patients with PD. Accordingly, our findings of alterations in MMP-2, MMP-9, and MMP-3 levels in the striatum of PD rats submitted to L-DOPA treatment consistent with the possibility that alterations in MMPs may contribute to LID pathogenesis.

\section{Antimicrobial drugs in Parkinson's disease}

There is evidence that antimicrobial drugs have the potential to exert neuroprotective effects on central nervous system neurodegenerative diseases, such as PD (Amor et al., 2010; 2014; Bassani et al., 2015; Bortolanza et al., 2018; Champagne-Jorgensen et al., 2019; Santa Cecilia et al., 2019).

The penicillin derivative ceftriaxone (beta-lactam antibiotic) has been found to prevent and reverse behavioral and neuronal deficits in the MPTP model of PD (Chotibut et al., 2014; Hsieh et al., 2017; Hsu, 2015; Huang et al., 2015; Weng et al., 2016). It increases the expression of glutamate transporter 1, which plays a major role in glutamate clearance in the central nervous system (Yimer et al., 2019). Ceftriaxone has been reported to slow the development of LID, but it does not change previously established LID (Chotibut et al. 2017; Kelsey and Neville 2014). The antibiotic poorly crosses the blood-brain barrier, and the concentrations used might be even higher than those for infectious disease treatment, thus exerting potent, selective pressure on commensal and pathogenic microbiota (Mattappalil and Mergenhagen, 2014).

Another first-line agent for the treatment of tuberculosis, rifampicin, readily crosses the blood-brain barrier and has also been used for the treatment of central nervous system infections (Yulug et al., 2014). Rifampicin 
reduces microglial inflammatory responses and neurodegeneration induced in vitro by $\alpha$-synuclein fibrillary aggregates (Acuña et al., 2019). Rifampicin pre-treatment inhibits the rotenone toxicity induced in the PC12 cells (Lin et al., 2017; Wu et al., 2018) and rotenone-induced microglial inflammation (Liang et al., 2017). Paradoxically, rifampicin possesses strong pro-inflammatory properties (Yuhas et al., 2009). It increases inducible nitric oxide synthase expression, NF- $x \mathrm{~B}$ activation, and decreases PPAR-g expression.

Doxycycline is one of the most extensively studied for properties other than its antimicrobial effects (Aminov, 2013; Chen et al., 2019; Stephenson et al., 2018), and excellent blood-brain barrier permeability (Barza et al., 1975; Liu et al., 2001). The drug is known to have a broad range of actions (Garrido-Mesa et al., 2013) including the modification of the neurotransmitters system known to be involved in the pathophysiology of LID such as the cholinergic (Conti et al., 2018; Schlesinger et al., 2004; Schlesinger et al., 2004), serotonergic (Zhang et al., 2006), glutamatergic (Monte et al., 2013) as well as others (Mansson et al., 2007; Munzar et al., 2002). In addition, González-Lizárraga et al. (2017) reported that doxycycline reshapes $\alpha$-synuclein oligomers, inhibits $\alpha$-synuclein aggregation, and the seeding of new oligomers, thus preventing cytotoxicity in dopaminergic cell lines.

The pharmacokinetic properties of doxycycline are advantageous concerning the gut microbiota. Based on their long, excellent safety profiles in humans, following oral application, the rapid rise in the serum levels indicates that it is primarily absorbed by the small intestine. Thus, doxycycline represents a low burden for the colorectal tract (Bartlett et al., 1975). As the motor benefits of L-DOPA were preserved after doxycycline treatment, it is strong evidence that the drug did not interfere with L-DOPA intestinal absorption. However, one cannot eliminate this hypothesis. New experiments are ongoing in our laboratory using the subcutaneous application of L-DOPA. Preliminary results confirm the outcome of oral L-DOPA. To avoid side effects related to the antimicrobial activity and possible bacterial resistance, chemically modified tetracycline COL-3 may have numerous applications without the associated risk of antibiotic resistance.

Finally, despite anecdotal evidence from patients with PD, we do not know to what extent the effects of doxycycline are valid. Although we have hypothesized that neuroinflammation plays a major role in the development of LID, we recognize that a causal link between the two needs to be firmly established. As a final point, repurposing doxycycline against dyskinesia in PD might be a novel tactic for neuroprotection, exploiting this therapeutic potential of a ready-to-use drug (Del Bel et al., 2016; Reglodi et al., 2017; Socias et al., 2018).

SUMMARY and CONCLUSION We demonstrated for the first time that doxycycline is effective in the attenuation of LID without interfering with the anti-akinetic action of L-DOPA. The possible mechanisms underlying the effect of doxycycline decreasing LID are interesting but need to be further investigated to optimize the dose and ensure the safety of long-term treatment. Our findings point to the potential of the repurposing doxycycline or its derivatives as an adjunct treatment to L-DOPA in the therapy of PD to delay the onset of dyskinesia and possibly attenuate neurodegeneration.

Ethics statement: The experiments were conducted according to the principles and procedures described by the guidelines for the care and use of animals in neuroscience and behavioral research (ILAR, USA). The local ethics committee approved the protocol.

Acknowledgments: The authors appreciate Prof. Francisco S Guimarães and Prof. Paul Bolam for their critical review of the paper. The authors would like to thank Célia A. da-Silva, Sara Saltareli, and Vitor Castania for their technical assistance.

Funding statement: The study was supported by the São Paulo State Foundation for the Support of Research (FAPESP, Brazil; Grant 2014/25029-4). EDB is a recipient of grants from the National Council for Scientific and Technological Development (CNPq, Brazil), CAPES, and the Comité Français d'Evaluation de la Coopération Universitaire avec le Brésil (French Committee for the Evaluation of Academic and Scientific Cooperation with Brazil; CAPES-COFECUB Grant \#848/15). EDB is a CNPq research fellow. MB and GCN were recipients of FAPESP, Brazil, fellowship 2016-06602-0 and 2015-03053-3, respectively). 
Conflict of interests: The authors have no financial or personal conflicts of interest to declare in relation to this study.

\section{Author's contribution}

Mariza Bortolanza: Conceptualization, Investigation, Experimental research, Formal Analysis, Writing: Original Draft Preparation, Review \& Editing

Glauce C do Nascimento: Experimental research, Formal Analysis; Writing: Original Draft Preparation, Review \& Editing

Rita Raisman-Vozari: Funding acquisition; Writing: Review \& Editing

Elaine Del Bel: Conceptualization, Investigation, Funding acquisition, Project administration, Supervision, Validation, Writing: Review \& Editing

DECLARATION OF TRANSPARENCY AND SCIENTIF IC RIGOUR This Declaration acknowledges that this paper adheres to the principles for transparent reporting and scientific rigour of preclinical research as stated in the BJP guidelines for Design Analysis, Immunoblotting and Immunochemistry, and Animal Experimentation, as recommended by funding agencies, publishers, and other organizations engaged with supporting research.

\section{Legend of the figures}

Figure 1. Doxycycline acute administration reduced LID without compromising the beneficial motor effects. 6-OHDA lesioned rats received a daily administration of L-DOPA $\left(20 \mathrm{mg} \mathrm{kg}^{-1}\right)$ for 14 days to establish the expression of L-DOPA induced dyskinesia.(A) Sum of the AIMs score or ALO AIMs (axial, forelimb, and orofacial) are presented. The score was measured on days 1, 7, 14 of L-DOPA administration $(\mathrm{n}=11)$ over $180 \mathrm{~min}$. Doxycycline was inoculated in the animal $30 \mathrm{~min}$ before L-DOPA (6OHDA+doxycycline+L-DOPA). AIMs expression decreased by $89 \%$ (one-way ANOVA-RM p $<0$. 0001; data presented as the mean+-SEM) compared to 6-OHDA+vehicle+L-DOPA. (B) Time course of the appearance of dyskinetic manifestation with 6-OHDA+doxycycline+L-DOPA compared to 6-OHDA+vehicle+L-DOPA $(\mathrm{p}<0.001)$ across time $(\mathrm{p}<0.05$, two-way ANOVA-RM followed by Bonferroni posthoc test). (C)L-DOPA administration significantly improved performance in the stepping test; doxycycline-maintained the beneficial LDOPA motor effects ( $\mathrm{p}<0.01$; one-way ANOVA followed by Bonferroni test; data are presented as the mean+SEM). (D) Doxycycline does not alter the L-DOPA effect on the distance traveled $(\mathrm{p}<0.0001$; one-way ANOVA followed by Bonferroni; data are presented as the mean+-SEM) *compared to 6-OHDA+vehicle+LDOPA; \#compared to 6-OHDA+doxycycline+L-DOPA $\Delta$ - compared to no-lesion+vehicle+vehicle. AIMs: abnormal involuntary movements; DOX: doxycycline; L-DOPA, L-3, 4-dihydroxyphenylalanine; RM, repeated measures; 6-OHDA, 6-hydroxydopamine.

Figure 2. Reduction of LID markers in the striatum of rats expressing LID after the acute administration of doxycyclinePhotomicrographs of the medial dorsal striatum (coronal sections - 0.10 $\mathrm{mm}$ with respect to bregma) from rats sacrificed $1 \mathrm{~h}$ after the last L-DOPA injection. Doxycycline treatment prior to L-DOPA reduced immunoreactivity for: $\operatorname{FosB}(\mathbf{A}, \mathbf{B})$; OX-42 (D, E) ; GFAP(G, H) and COX-2 $(\mathbf{J}, \mathbf{K})$. The bar charts (C, F, I, L, respectively) show the quantification of FosB, OX-42, GFAP, and COX-2 immunopositive cells. 6-OHDA+vehicle+L-DOPA group is represented in $(\mathbf{A}, \mathbf{D}, \mathbf{G}, \mathbf{J})$ and 6 OHDA+doxycycline+L-DOPA in $(\mathbf{B}, \mathbf{E}, \mathbf{H}, \mathbf{K})$. A two-way ANOVA followed by the Bonferroni test was used to check for statistical significance $(\mathrm{p}<0.05)$; $=7-10 /$ group; *compared to 6-OHDA+vehicle+vehicle; \#compared to 6-OHDA+vehicle+L-DOPA; OX-42, CD11b/c beta-integrin marker of microglia; GFAP, glial fibrillary acid protein; COX-2, cyclooxygenase-2. Inset bar: $10 \mu \mathrm{m}$.

Figure 3. Reduction of ROS and MMPs in the striatum of rats expressing LID after the acute administration of doxycycline. ROS, MMP-2/MMP-9, and MMP-3 levels increased in the striatum of rats with dyskinesia that was decreased by doxycycline. (A-F)Representative image from the dopaminedenervated striatum of L-DOPA-treated rats (-0.10 mm relative to bregma; Paxinos and Watson, 1997) 
without and with doxycycline treatment illustrating ROS (redA-C ) and MMP-2/MMP-9 gelatinolytic activity (green D - F ) expressed as arbitrary fluorescence units. The graphics show the quantification of ROS and MMP activity $(\mathbf{G}, \mathbf{I}, \mathbf{K})$ and the correlation between them and the dyskinesia index $(\mathbf{H}$, $\mathbf{J}, \mathbf{L})$. The 6-OHDA+vehicle+vehicle group is represented in (A, D); 6-OHDA+vehicle+L-DOPA in (B, E) and 6-OHDA+doxycycline+L-DOPA in $(\mathrm{C}, \mathrm{F})$. A one-way ANOVA followed by the Bonferroni test was used to check for statistical significance $(\mathrm{p}<0.05)$. There was no correlation between the dyskinesia sum of the score of rats and ROS fluorescence intensity $(\mathrm{p}=0.3 ; \mathrm{r}=0.3 ; \mathbf{H})$. Pearson's correlation coefficient was significant between the sum of the dyskinesia score and gelatinolytic activity $(\mathrm{p}<0.0001$; $\mathrm{r}=0.9 ; \mathbf{J})$. MMP-3 expression $(\mathrm{p}<0.0001, \mathrm{r}=0.9, \mathbf{L})$ was revealed. Each point represents an individual rat. *compared to 6-OHDA+vehicle+vehicle; \#compared to 6-OHDA+vehicle+L-DOPA; $\Delta$ compared to no-lesion+vehicle+vehicle ( $\mathrm{n}=6-7$ /group). AIMs, abnormal involuntary movements; DOX, doxycycline; LDOPA, L-3,4-dihydroxyphenylalanine; MMP, matrix metalloproteinase; ROS, reactive oxygen species.

Figure 4. Doxycycline/L-DOPA chronic co-treatment of parkinsonian rats since the first day of receiving L-DOPA block LID development and the increase of ROS and MMPs in the striatum (A)Cumulative total score of the axial, limb and orofacial AIMs evaluated on days 1, 7, and 14 after L-DOPA treatment. Doxycycline co-treatment blocked the development of L-DOPA induced dyskinesia $(\mathrm{p}<0.0001$, two-way ANOVA-RM, Bonferroni posthoc test). Data are presented as the mean \pm SEM. (E, F, G) Representative images from the dopamine-denervated striatum of rats $(-0.10 \mathrm{~mm}$ relative to bregma) illustrating ROS detection (red C, D ) and MMP-2/-9 gelatinolytic activity (green $\mathbf{F}, \mathbf{H}$ ) measured as arbitrary fluorescence units. The 6-OHDA+chronic-vehicle+vehicle group is shown in $(\mathbf{C}, \mathbf{F}) ; 6$-OHDA+chronic-vehicle+L-DOPA in $(\mathbf{D}, \mathbf{G})$ and 6-OHDA+chronic-doxycycline+L-DOPA in $(\mathrm{E}, \mathrm{H})$. The graphics show the quantification of ROS and MMP activity (I, K) and the correlation between them and the dyskinesia index (J, L) . A oneway ANOVA followed by the Bonferroni test was used to check for statistical significance $(\mathrm{p}<0.05)$. Pearson's correlation coefficient was significant between AIMs intensity and ROS $(p<0.0001 ; r=0.9)$ and AIMs intensity and gelatinolytic activity $(\mathrm{p}<0.0001, \mathrm{r}=0.7)$. All molecular markers are expressed in the denervated striatal areas. * compared to 6-OHDA+chronic-vehicle+vehicle; \#compared to 6-OHDA+chronic-vehicle+L-DOPA; $\Delta$ compared to no-lesion+chronic-vehicle+vehicle; +compared to 6-OHDA+chronic-vehicle+L-DOPA at 1 Day of treatment; \&compared to 6-OHDA+chronic-vehicle+L-DOPA at 7 Days of treatment (n=6-7/group) AIMS, abnormal involuntary movements; L-DOPA, L-3,4-dihydroxyphenylalanine; MMP, matrix metalloproteinase; ROS, reactive oxygen species; chDOX, chronic doxycycline.

Figure 5. COL-3 acute administration reduces LID in animals expressing LID. After L-DOPA induced dyskinesia had been established, the animals received two different doses of COL3 (50 or $100 \mathrm{nmol}$ approximately 0.1 and $0.2 \mu \mathrm{g} \mathrm{Kg}-1$ intracerebroventricular) before L-DOPA. (A) Sum of the AIMs score (axial, forelimb, and orofacial) are presented. COL-3 $(100 \mathrm{nmol})$ treatment significantly reduced the sum of AIMs over the 180 min observation period $(\mathrm{p}<0$. 01; paired t-test $\mathrm{n}=5 ; \mathrm{p}<0.05 \mathrm{RM}$ one-way ANOVA $\mathrm{n}=7$ ) compared to the measurement the previous day. The points represent data from individual animals.(B) Time course of the appearance of dyskinesia with 6-OHDA+COL-3+L-DOPA compared to 6-OHDA+vehicle+LDOPA across the time period ( $\mathrm{p}<0.01$, two-way ANOVA-RM followed by Bonferroni posthoc test). AIMS were evaluated on days 1, 7, and 14. Data are expressed as the mean \pm SEM; $p<0.05$ \#compared to 6OHDA+vehicle+L-DOPA. AIMs, axial, limb and orofacial abnormal involuntary movements; COL-3, CMT3,6-demethyl-6-deoxy-4-de[dimethylamino]-tetracycline; L-DOPA, L-3,4-dihydroxyphenylalanine; VEH, vehicle.

\section{SUPPLEMENTARY FIGURE LEGEND}

Suppl. Figure 1. Photomicrography of coronal brain sections illustrating the loss of striatum TH positive fibers (A-C; A'-C) and substantia nigra compacta TH positive neurons (D-F; D'-F); (A', B', C', D', E', F') represents the lesion side. Scale bars $=1200 \mu \mathrm{m}$.

Suppl. Figure 2. Doxycycline or COL-3 single administration to L-DOPA primed rats or co-administration of L-DOPA and doxycycline reduces individual AIMs development. (A, B, C) show doxycycline single administration effects on axial $(\mathrm{p}=0.069)$, limb $(\mathrm{p}<0.01)$ and orofacial $(\mathrm{p}<0.05)$ AIMs, respectively 
over $60 \mathrm{~min}$ on day 15 compared to day 14 LID measurement (paired t-test; the points represent data from individual animals). (D, E, F) show the co-administration of L-DOPA and doxycycline effects on the axial, limb, and orofacial AIMs, respectively over $60 \mathrm{~min}(\mathrm{p}<0.0001$, unpaired t-test, data as box and whiskers plus minimum and maximum values, the point values represent data from individual animals). $(\mathrm{G}, \mathrm{H}, \mathrm{I})$ show COL-3 single intraventricular administration effects on axial $(\mathrm{p}<0.01)$, limb $(\mathrm{p}<0.01)$ and orofacial $(\mathrm{p}<0.05) \mathrm{AIMs}$, respectively over $60 \mathrm{~min}$ on day 15 compared to day 14 (paired t-test; the points represent data from individual animals). \#compared to 6-OHDA+vehicle+L-DOPA; +compared to 6-OHDA+vehicle+L-DOPA. AIMs: abnormal involuntary movements; DOX: doxycycline; L-DOPA, L-3,4dihydroxyphenylalanine.

Suppl. Figure 3. Morphological quantification of the astrocytes and microglia reactivity. Doxycycline reduces activation of the astrocytes (GFAP, glial fibrillary acid protein labeling astrocytes) and microglia (OX-42 CD11b/c-beta-integrin marker of microglia) associated with LID. The analysis was performed in the striatum of 6-OHDA-lesioned rats expressing LID, without and with doxycycline treatment. Animals were sacrificed $1 \mathrm{~h}$ after the last L-DOPA injection. Morphological quantification of the GFAP and OX42 reactivity is shown in the bar charts and represents the average process number $(\mathbf{A})$ (D), average process length (B) (E), and process intersection number (C) (F), respectively. A two-way ANOVA followed by the Bonferroni test was used to check for statistical significance: *compared to 6 -OHDA+vehicle+vehicle; \#compared to 6-OHDA+vehicle+L-DOPA.

Suppl. Figure 4. Substrate gel zymography quantification of striatal MMP-2 and MMP-9 isoforms, following acute and chronic doxycycline administration in parkinsonian rats (A-B) : 6-OHDA-lesion and L-DOPA treatment increased MMP-2 and MMP-9 in the striatum. A single dose of doxycycline reduced MMP-9 in the striatum of lesioned rats, and L-DOPA treated rats. (C-D): The administration of L-DOPA increased the presence of MMP-2 and MMP-9 in the lesioned striatum. The co-administration of doxycycline during L-DOPA (or its vehicle) treatment reduced both MMP-2 and MMP-9 in the striatum of lesioned rats, and L-DOPA treated rats. A one-way ANOVA followed by a Bonferroni test was used to check for statistical significance $(\mathrm{p}<0.05)$. ${ }^{*}$ compared to 6 -OHDA+vehicle+vehicle; \#compared to 6-OHDA+vehicle+L-DOPA. AIMs abnormal involuntary movements; DOX, doxycycline; L-DOPA, L-3,4-dihydroxyphenylalanine; MMPs, matrix metalloproteinase

\section{REFERENCES}

1. Acuña, L., Hamadat, S., Corbalán, N.S., González-Lizárraga, F., Dos-Santos-Pereira, M., Rocca, J., Díaz, J.S., Del-Bel, E., Papy-García, D., Chehín, R.N., Michel, P.P., Raisman-Vozari, R., 2019. Rifampicin and Its Derivative Rifampicin Quinone Reduce Microglial Inflammatory Responses and Neurodegeneration Induced In Vitro by $\alpha$-Synuclein Fibrillary Aggregates. Cells. 8(8):776. doi: $10.3390 /$ cells 8080776 .

2. Aminov, R.I., 2013. Biotic acts of antibiotics. Front.Microbiol 4:241 10.3389/fmicb.2013.00241. doi: 10.3389/fmicb.2013.00241.

3. Amor, S., Puentes, F., Baker, D., van der Valk, P., 2010. Inflammation in neurodegenerative diseases. Immunology. 129(2): 154-169. doi:10.1111/j.1365-2567.2009.03225.x.

4. Amor. S., Peferoen, L.A ., Vogel, D.Y., Breur, M., van der Valk, P., Baker, D., van Noort, J.M., 2014. Inflammation in neurodegenerative diseases-an update. Immunology. 142(2): 151-166. doi:10.1111/imm.12233.

5. Anderson, J.M., Hughes, J.D., Gonzalez, Rothi. L.J., Crucian, G.P., Heilman, K.M., 1999. Developmental stuttering and Parkinson's disease: The effects of levodopa treatment. Journal of Neurology Neurosurgery and Psychiatry. 66(6):776-8. doi: 10.1136/jnnp.66.6.776.

6. Andersson, H., Alestig, K., 1976. The penetration of doxycycline into CSF. Scand J Infect Dis Suppl. (9):17-9.

7. Annese, V., Herrero, M.T., Di Pentima, M., Gomez, A., Lombardi, L., Ros, C.M., De Pablos, V., Fernandez-Villalba, E., De Stefano, M.E., 2015. Metalloproteinase-9 contributes to inflammatory glia activation and nigrostriatal pathway degeneration in both mouse and monkey models of 1-methyl- 
4-phenyl-1,2,3,6-tetrahydropyridine (MPTP)-induced Parkinsonism. Brain Structure and Function. 220(2): 703-727. doi: 10.1007/s00429-014-0718-8.

8. Antonio, R.C., Ceron, C.S., Rizzi, E., Coelho, E.B., Tanus-Santos, J.E., Gerlach, R.F., 2014. Antioxidant effect of doxycycline decreases MMP activity and blood pressure in SHR. Molecular and Cellular Biochemistry. 386(1-2): 99-105. doi: 10.1007/s11010-013-1848-7.

9. Aquino, C.C., Fox, S.H., 2015. Clinical spectrum of levodopa-induced complications. Mov Disord. 30(1):80-9. doi: $10.1002 / \mathrm{mds} .26125$.

10. Aron Badin, R., Spinnewyn, B., Gaillard, M.C., Jan, C., Malgorn, C., van Camp, N., et al., 2013. IRC082451, a Novel Multitargeting Molecule, Reduces L-DOPA-Induced Dyskinesias in MPTP Parkinsonian Primates. PLoS ONE. 8(1): e52680. doi: 10.1371/journal.pone.0052680.

11. Bahrami, F.L., Morris, D.H., Pourgholami, M., 2011. Tetracyclines: Drugs with Huge Therapeutic Potential. Mini-Reviews in Medicinal Chemistry. 12: 44-52. doi: 10.2174/138955712798868977.

12. Barcia, C., Fernández Barreiro, A., Poza, M., Herrero, M.T., 2003. Parkinson's disease and inflammatory changes. Neurotox Res. 5(6):411-8. doi: 10.1007/BF03033170.

13. Barnum, C.J., Eskow, K.L., Dupre, K., Blandino, P.Jr., Deak, T., Bishop, C., 2008. Exogenous corticosterone reduces L-DOPA-induced dyskinesia in the hemi-parkinsonian rat: role for IL-1beta. Neuroscience. 156(1): 30-41. doi: 10.1016/j.neuroscience.2008.07.016.

14. Bartels, A.L., Leenders, K.L., 2007. Neuroinflammation in the pathophysiology of Parkinson's disease: evidence from animal models to human in vivo studies with [11C]-PK11195 PET. Mov Disord. 22(13):1852-6. doi: 10.1002/mds.21552.

15. Bartlett, J.G., Bustetter, L.A., Gorbach, S.L., Onderdonk, A.B., 1975. Comparative effect of tetracycline and doxycycline on the occurrence of resistant Escherichia coli in the fecal flora. Antimicrob Agents Chemother. 7: 55-57. doi: 10.1128/aac.7.1.55.

16. Barza, M., Brown, R.B., Shanks, C., Gamble, C., Weinstein L., 1975. Relation between lipophilicity and pharmacological behavior of minocycline, doxycycline, tetracycline, and oxytetracycline in dogs. Antimicrob Agents Chemother. 8(6):713-20. doi: 10.1128/aac.8.6.713.

17. Bassani, T.B., Vital, M.A., Rauh, L.K., 2015. Neuroinflammation in the pathophysiology of Parkinson's disease and therapeutic evidence of anti-inflammatory drugs. Arq Neuropsiquiatr. 73:616-623. doi: 10.1590/0004-282X20150057.

18. Ben Haim, L., Carrillo-de Sauvage, M.A., Ceyzériat, K., and Escartin, C., 2015. Elusive roles for reactive astrocytes in neurodegenerative diseases. Front. Cell. Neurosci. 9:278. doi: 10.3389/fncel.2015.00278. eCollection 2015.

19. Berke, J.D., Paletzki, R.F., Aronson, G.J., Hyman, S.E., Gerfen, C.R., 1998. J Neurosci. A complex program of striatal gene expression induced by dopaminergic stimulation. 18(14):5301-10. doi: 10.1523/JNEUROSCI.18-14-05301.1998.

20. Blanchet, P.J., Konitsiotis, S., Chase, T.N., 1998. Amantadine reduces levodopa-induced dyskinesias in parkinsonian monkeys. Mov Disord. 13(5):798-802.

21. Boi, L., Pisanu, A., Greig, N.H., Scerba, M.T., Tweedie, D., Mulas, G., Fenu, S., Carboni, E., Spiga, S., Carta, A.R., 2019. Immunomodulatory drugs alleviate l-dopa-induced dyskinesia in a rat model of Parkinson's disease. Mov Disord. 34(12):1818-1830. doi: 10.1002/mds.27799.

22. Borgkvist, A., Lieberman, O.J., Sulzer, D., 2018. Synaptic plasticity may underlie l-DOPA induced dyskinesia. Curr Opin Neurobiol. 48:71-78. doi: 10.1016/j.conb.2017.10.021.

23. Bortolanza, M., Cavalcanti-Kiwiatkoski. R., Padovan-Neto, F.E., da-Silva, C.A., Mitkovski, M., Raisman-Vozari R., Del-Bel, E., 2015. Glial activation is associated with l-DOPA induced dyskinesia and blocked by a nitric oxide synthase inhibitor in a rat model of Parkinson's disease. Neurobiology of Disease. 73:377-87. doi: 10.1016/j.nbd.2014.10.017.

24. Bortolanza, M., Nascimento, G.C., Socias, S.B., Ploper, D., Chehín, R.N., Raisman-Vozari, R., DelBel, E., 2018. Tetracycline repurposing in neurodegeneration: focus on Parkinson's disease. Journal of Neural Transmission. 125(10):1403-1415. doi: 10.1007/s00702-018-1913-1.

25. Bortolanza, M., Padovan-Neto, F.E., Cavalcanti-Kiwiatkoski, R., Dos Santos-Pereira, M., Mitkovski, M., Raisman-Vozari, R., Del-Bel, E., 2015. Are cyclooxygenase-2 and nitric oxide involved in the 
dyskinesia of parkinson's disease induced by L-DOPA? Philosophical Transactions of the Royal Society B: Biological Sciences. 370(1672): 20140190. doi: 10.1098/rstb.2014.0190.

26. Braak, H., Del Tredici, K., 2008. Invited Article: Nervous system pathology in sporadic Parkinson disease. Neurology. 70(20): 1916-1625. doi: 10.1212/01.wnl.0000312279.49272.9f.

27. Bradford, M.M., 1976. A rapid and sensitive method for the quantitation of microgram quantities of protein utilizing the principle of protein-dye binding. Anal Biochem. 72: 248-254. doi: 10.1006/abio.1976.9999.

28. Bredberg, E., Lennernäs, H., Paalzow, L., 1994. Pharmacokinetics of levodopa and carbidopa in rats following different routes of administration. Pharm Res. 11(4):549-555. doi:10.1023/a:1018970617104.

29. Calabresi, P., Ghiglieri, V., Mazzocchetti, P., Corbelli, I., Picconi, B., 2015. Levodopa-induced plasticity: a double-edged sword in Parkinson's disease? Philos Trans R Soc Lond B Biol Sci. 370(1672): 20140184. doi: 10.1098/rstb.2014.0184.

30. Carta, A.R., Mulas, G., Bortolanza, M., Duarte, T., Pillai, E., Fisone, G., Vozari, R.R., Del-Bel, E., 2017. l-DOPA-induced dyskinesia and neuroinflammation: do microglia and astrocytes play a role? Eur J Neurosci. 45(1):73-91. doi: 10.1111/ejn.13482.

31. Castro, M.M., Rizzi, E., Rodrigues, G.J., Ceron, C.S., Bendhack, L.M., Gerlach, R.F., et al., 2009. Antioxidant treatment reduces matrix metalloproteinase-2-induced vascular changes in renovascular hypertension. Free Radical Biology and Medicine. 160(1): 77-87. doi: 10.1111/j.1476-5381.2010.00678. $\mathrm{x}$.

32. Cenci, M.A., 2007. L-DOPA-induced dyskinesia: cellular mechanisms and approaches to treatment. Parkinsonism Relat Disord. 13 Suppl 3: S263-7. doi: 10.1016/S1353-8020(08)70014-2.

33. Cenci, M.A., 2014. Presynaptic Mechanisms of l-DOPA-Induced Dyskinesia: The Findings, the Debate, and the Therapeutic Implications. Front Neurol. 5:242. doi: 10.3389/fneur.2014.00242.

34. Cenci, M.A., Crossman, A.R., 2018. Animal models of l-dopa-induced dyskinesia in Parkinson's disease. Mov Disord. 33(6):889-899. doi: 10.1002/mds.27337.

35. Cenci, M.A., Lee, C.S., Bjorklund, A., 1998. L-DOPA-induced dyskinesia in the rat is associated with striatal overexpression of prodynorphin- and glutamic acid decarboxylase mRNA. European Journal of Neuroscience. 10(8):2694-706

36. Cenci, M.A., Lundblad, M., 2007. Ratings of L-DOPA-induced dyskinesia in the unilateral 6-OHDA lesion model of Parkinson's disease in rats and mice. Curr Protoc Neurosci. Chapter 9:Unit 9.25. doi: 10.1002/0471142301.ns0925s41.

37. Cenci, M.A., Olanow, C.W., 2017. Translating scientific advances into disease-modifying therapies for Parkinson's Disease. Exp Neurol. 298(Pt B):135-136. doi: 10.1016/j.expneurol.2017.10.011.

38. Cenci, M.A., Riggare, S., Pahwa, R., Eidelberg, D., Hauser, R.A., 2020. Dyskinesia matters. Mov Disord. 35(3):392-396.

39. Champagne-Jorgensen et al., 2019. Antibiotics and the nervous system: More than just the microbes? Brain Behav Immun. 77:7-15. doi: 10.1016/j.bbi.2018.12.014.

40. Chang, J.W., Wachtel, S.R., Young, D., Kang, U.J., 1999. Biochemical and anatomical characterization of forepaw adjusting steps in rat models of Parkinson's disease: studies on medial forebrain bundle and striatal lesions. Neuroscience. 88(2):617-28. doi: 10.1016/s0306-4522(98)00217-6.

41. Charvin, D., Medori, R., Hauser, R. et al., 2018. Therapeutic strategies for Parkinson disease: beyond dopaminergic drugs. Nat Rev Drug Discov. 17, 804-822. doi: 10.1038/nrd.2018.136.

42. Chen, X., Gumina, G., Virga, K.G., 2019. "Recent Advances in Drug Repurposing for Parkinson's Disease", Current Medicinal Chemistry. 26: 5340.

43. Choi, D.H., Kim, J.H., Seo, J.H., Lee, J., Choi, W.S., Kim, Y.S., 2014. Matrix metalloproteinase3 causes dopaminergic neuronal death through nox1-regenerated oxidative stress. PLoS ONE. 9(12):e115954. doi: 10.1371/journal.pone.0115954.

44. Choi, D.H., Kim, Y.J., Kim, Y.G., Joh, T.H., Beal, M.F., Kim, Y.S., 2011. Role of matrix metalloproteinase 3-mediated $\alpha$-synuclein cleavage in dopaminergic cell death. Journal of Biological Chemistry. 286(16):14168-77. doi: 10.1074/jbc.M111.222430.

45. Chotibut, T., Davis, R.W., Arnold, J.C., et al., 2014. Ceftriaxone increases glutamate uptake and 
reduces striatal tyrosine hydroxylase loss in 6-OHDA Parkinson's model. Mol Neurobiol. 49: 12821292. doi: 10.1007/s12035-013-8598-0.

46. Chotibut, T., Meadows, S., Kasanga, E.A., McInnis, T., Cantu, M.A., Bishop, C., Salvatore, M.F., 2017. Ceftriaxone reduces L-dopa-induced dyskinesia severity in 6-hydroxydopamine parkinson's disease model. Mov Disord. 32(11):1547-1556. doi: 10.1002/mds.27077.

47. Chung, Y.C., Kim, Y.S., Bok, E, et al., 2013. MMP-3 contributes to nigrostriatal dopaminergic neuronal loss, BBB damage, and neuroinflammation in an MPTP mouse model of Parkinson's disease. Mediators Inflamm. 2013: 370526. doi: 10.1155/2013/370526.

48. Conti, M.M., Chambers, N., Bishop, C.A., 2018. New outlook on cholinergic interneurons in Parkinson's disease and L-DOPA-induced dyskinesia. Neurosci Biobehav Rev. 92:67-82. doi: 10.1016/j.neubiorev.2018.05.021.

49. De Meira Santos Lima, M., Reksidler, M.A.B., Zanata, S.M., Bueno, H., Machado, S., Tufik, M.A., 2006. Vital Different parkinsonism models produce a time-dependent induction of COX-2 in the substantia nigra of rats Brain Res. 1101:117-125. doi: 10.1016/j.brainres.2006.05.016

50. De Stefano, M.E., Herrero, M.T., 2017. The multifaceted role of metalloproteinases in physiological and pathological conditions in embryonic and adult brains. Prog Neurobiol. 155:36-56. doi: 10.1016/j.pneurobio.2016.08.002

51. Del-Bel, E., Bortolanza, M., Dos-Santos-Pereira, M., Bariotto, K., Raisman-Vozari, R., 2016. IDOPAinduced dyskinesia in Parkinson's disease: Are neuroinflammation and astrocytes key elements? Synapse. 70(12):479-500. doi: 10.1002/syn.21941

52. dos-Santos-Pereira, M., da-Silva, C.A., Guimarães, F.S., Del-Bel, E., 2016. Co-administration of cannabidiol and capsazepine reduces L-DOPA-induced dyskinesia in mice: Possible mechanism of action. Neurobiology of Disease. 94:179-95. doi: 10.1016/j.nbd.2016.06.013.

53. Du, Y., Ma, Z., Lin, S., Dodel, R.C., Gao, F., Bales, K.R., et al., 2001. Minocycline prevents nigrostriatal dopaminergic neurodegeneration in the MPTP model of Parkinson's disease. Proceedings of the National Academy of Sciences of the United States of America. 98(25):14669-74. doi: 10.1073/pnas.251341998.

54. Edan, R.A., Luqmani, Y.A., Masocha, W., 2013. COL-3, a chemically modified tetracycline, inhibits lipopolysaccharide-induced microglia activation and cytokine expression in the brain. PLoS One. 8(2): e57827. doi:10.1371/journal.pone.0057827.

55. Egeberg, A., Hansen, P.R., Gislason, G.H., Thyssen, J.P., 2016. Exploring the association between rosacea and Parkinson disease: A Danish nationwide cohort study. JAMA Neurology. 73(5):529-34. doi: 10.1001/jamaneurol.2016.0022.

56. Espadas, I., Keifman, E., Palomo-Garo, C., Burgaz, S., García, C., Fernández-Ruiz, J., Moratalla, R., 2020. Beneficial effects of the phytocannabinoid $\Delta 9$-THCV in L-DOPA-induced dyskinesia in Parkinson's disease. Neurobiol Dis. 141:104892. doi: 10.1016/j.nbd.2020.104892.

57. Espay, A.J., Morgante, F., Merola, A., Fasano, A., Marsili, L., Fox, S.H., Bezard, E., Picconi, B., Calabresi, P., Lang, A.E., 2018. Levodopa-induced dyskinesia in Parkinson disease: Current and evolving concepts. Ann Neurol. 84(6):797-811. doi: 10.1002/ana.25364.

58. Fahn, S., Oakes, D., Shoulson, I., Kieburtz, K., Rudolph, A., Lang, A., Olanow, C.W., Tanner, C., Marek, K., 2004. Parkinson Study Group. Levodopa and the progression of Parkinson's disease. N Engl J Med. 351(24):2498-508. doi: 10.1056/NEJMoa033447.

59. Fernández, R.A.R., Pereira, Y.C.L., Iyomasa. D.M., Calzzani, R.A., Leite-Panissi, C.R.A., Iyomasa, M.M., et al., 2018. Metabolic and vascular pattern in medial pterygoid muscle is altered by chronic stress in an animal model of hypodontia. Physiology and Behavior. 185: 70-78. doi: 10.1016/j.physbeh.2017.12.026.

60. Galis, Z.S., Sukhova, G.K., Libby, P., 1995. Microscopic localization of active proteases by in situ zymography: detection of matrix metalloproteinase activity in vascular tissue. FASEBJ. 9: 974-980. doi: $10.1096 /$ fasebj.9.10.7615167.

61. Garcia-Martinez, E.M., Sanz-Blasco, S., Karachitos, A., Bandez, M.J., Fernandez-Gomez, F.J., Perez-Alvarez, S., et al., 2010. Mitochondria and calcium flux as targets of neuroprotection 
caused by minocycline in cerebellar granule cells. Biochemical Pharmacology. 79(2):239-50. doi: 10.1016/j.bcp.2009.07.028.

62. Gearing, P. Beckett, M. Christodoulou, M. Churchill, J.M. Clements, M. Crimmin, A.H. Davidson, A.H. Drummond, W.A. Galloway, R. Gilbert, et al., 1995. Matrix metalloproteinases and processing of pro-TNF-alpha J. Leukoc. Biol. 57:74-777. doi: 10.1002/jlb.57.5.774.

63. Gerhard, A., Pavese, N., Hotton, G., Turkheimer, F., Es, M., Hammers, A., Eggert, K., Oertel, W., Banati, R.B., Brooks, D.J., 2006. In vivo imaging of microglial activation with [11C](R)-PK11195 PET in idiopathic Parkinson's disease. Neurobiol Dis. 21:404-412. doi: 10.1016/j.nbd.2005.08.002.

64. Giocanti-Auregan, A., Vacca, O., Benard, R., Cao, S., Siqueiros, L., Montanez, C., Paques, M., Sahel, J.A., Sennlaub, F., Guillonneau, X., Rendon, A., Tadayoni, R., 2016. Altered astrocyte morphology and vascular development in dystrophin-Dp71-null mice. Glia. 64(5):716-29. doi: 10.1002/glia.22956

65. Gomes, M.Z., Del Bel, E.A., 2003. Effects of electrolytic and 6-hydroxydopamine lesions of rat nigrostriatal pathway on nitric oxide synthase and nicotinamide adenine dinucleotide phosphate diaphorase. Brain Res Bull. 62(2):107-15. doi: 10.1016/j.brainresbull.2003.08.010.

66. Gomes, M.Z., Raisman-Vozari, R., Del Bel, E.A., 2008. A nitric oxide synthase inhibitor decreases 6-hydroxydopamine effects on tyrosine hydroxylase and neuronal nitric oxide synthase in the rat nigrostriatal pathway. Brain Research. 1203: 160-169. doi: 10.1016/j.brainres.2008.01.088.

67. Gompels, L.L., Smith, A., Charles, P.J., Rogers, W., Soon-Shiong, J., Mitchell, A., et al., 2006. Single-blind randomized trial of combination antibiotic therapy in rheumatoid arthritis. J Rheumatol. 33(2):224-7.

68. Gonzalez-Lizarraga, F., Socias, S.B., Avila, C.L., Torres-Bugeau, C.M., Barbosa, L.R., Binolfi, A., Sepulveda-Diaz, J.E., Del-Bel, E., Fernandez, C.O., Papy-Garcia, D., Itri, R., RaismanVozari, R., Chehin, R.N., 2017. Repurposing doxycycline for synucleinopathies: remodelling of $\alpha$ synuclein oligomers towards non-toxic parallel beta-sheet structured species. Sci Rep. 7:41755. doi: $10.1038 /$ srep41755

69. Gottschall, P.E., Yu, X., 1995. Cytokines regulate gelatinase A and B (matrix metalloproteinase 2 and 9) activity in cultured rat astrocytes Journal of Neurochemistry. 64(4): 1513-1520. doi: 10.1046/j.1471-4159.1995.64041513. x.

70. Hsieh, M.H., Meng, W.Y., Liao, W.C., Weng, J.C., Li, H.H., Su, H.L., Lin, C.L., Hung, C.S., Ho, Y.J., 2017. Ceftriaxone reverses deficits of behavior and neurogenesis in an MPTP-induced rat model of Parkinson's disease dementia. Brain Res Bull. 132: 129-138. doi: 10.1016/j.brainresbull.2017.05.015.

71. Hsu, C.Y., Hung, C.S., Chang, H.M., Liao, W.C., Ho, S.C., Ho, Y.J., 2015. Ceftriaxone prevents and reverses behavioral and neuronal deficits in an MPTP-induced animal model of Parkinson's disease dementia. Neuropharmacology. 91:43-56. doi: 10.1016/j.neuropharm.2014.11.023.

72. Huang, C.K., Chang, Y.T., Amstislavskaya, T.G., Tikhonova, M.A., Lin, C.L., Hung, C.S., Lai, T.J., Ho, Y.J., 2015. Synergistic effects of ceftriaxone and erythropoietin on neuronal and behavioral deficits in an MPTP-induced animal model of Parkinson's disease dementia. Behav Brain Res. 294: 198-207. doi: $10.1016 /$ j.bbr.2015.08.011.

73. Huot, P., Johnston, T.H., Koprich, J.B., Fox, S.H., Brotchie, J.M., 2013. The pharmacology of L-DOPA-induced dyskinesia in Parkinson's disease. Pharmacol Rev. 65(1):171-222. doi: $10.1124 /$ pr.111.005678.

74. Itoh, H. Nagase, I.B. Thogersen, J.J. Enghild, Y. Sasaguri, Y. M., 1996. Degradation of interleukin 1beta by matrix metalloproteinases J. Biol. Chem. 271:14657-14660. doi: 10.1074/jbc.271.25.14657.

75. Janelidze, S., Lindqvist, D., Francardo, V., Hall, S., Zetterberg, H., Blennow, K., Adler, C.H., Beach, T.G., Serrano, G.E., van Westen, D., Londos, E., Cenci, M.A., Hansson, O., 2015. Increased CSF biomarkers of angiogenesis in Parkinson disease. Neurology. 85(21):1834-42. doi: 10.1212/WNL.0000000000002151.

76. Jenner, P., 2008. Molecular mechanisms of L-DOPA-induced dyskinesia. Nat Rev Neurosci. 9(9):66577. doi: 10.1038/nrn2471.

77. Jenner, P., Olanow, C.W., 1996. Oxidative stress and the pathogenesis of Parkinson's disease. Neurology. 47(6 Suppl 3): S161-S170. doi:10.1212/wnl.47.6_suppl_3.161s. 
78. Johnston, T.H., Lacoste, A.M.B., Visanji, N.P., Lang, A.E., Fox, S.H., Brotchie, J.M., 2019. Repurposing drugs to treat l-DOPA-induced dyskinesia in Parkinson's disease. Neuropharmacology. 147:11-27. doi: 10.1016/j.neuropharm.2018.05.035.

79. Johnston, T.H., Versi, E., Howson, P.A., Ravenscroft, P., Fox, S.H., Hill, M.P., Reidenberg, B.E., Corey. R., Brotchie, J.M., 2018. DPI-289, a novel mixed delta opioid agonist / mu opioid antagonist (DAMA), has L-DOPA-sparing potential in Parkinson's disease. Neuropharmacology. 131:116-127. doi: $10.1016 /$ j.neuropharm.2017.11.046..

80. Kelsey, J.E., Neville C., 2014. The effects of the $\beta$-lactam antibiotic, ceftriaxone, on forepaw stepping and l-DOPA-induced dyskinesia in a rodent model of Parkinson's disease. Psychopharmacology. 231(12):2405-15. doi: 10.1007/s00213-013-3400-6.

81. Kettenmann, H., Hanisch, U.K., Noda, M., Verkhratsky, A., 2011. Physiology of microglia. Physiol Rev. 91(2):461-553. doi: 10.1152/physrev.00011.2010.

82. Kim, E.M., Shin, E.J., Choi, J.H., Son, H.J., Park, I.S., Joh, T.H., Hwang, O., 2010. Matrix metalloproteinase-3 is increased and participates in neuronal apoptotic signaling downstream of caspase- 12 during endoplasmic reticulum stress. J. Biol. Chem. 285:16444-52. doi: 10.1074/jbc.M109.093799.

83. Kim, J.H., Lee, H.W., Hwang, J., Kim, J., Lee, M., Han, H., Lee, W., Suk, K., 2012. Microgliainhibiting activity of Parkinson's disease drug amantadine. Neurobiol Aging. 33(9): 2145-2159. doi: 10.1016/j.neurobiolaging.2011.08.011.

84. Kim, Y.S., Choi, D.H., Block, M.L., Lorenzl, S., Yang, L., Kim, Y.J., et al., 2007. A pivotal role of matrix metalloproteinase-3 activity in dopaminergic neuronal degeneration via microglial activation. FASEB J. 21:179-87. doi: 10.1096/fj.06-5865com.

85. Kirik, D., Rosenblad, C., Björklund A., 1998. Characterization of behavioral and neurodegenerative changes following partial lesions of the nigrostriatal dopamine system induced by intrastriatal 6hydroxydopamine in the rat. Exp Neurol. 152(2):259-77. doi: 10.1006/exnr.1998.6848.

86. Klein, N.C., Cunha, B.A., 1995. Tetracyclines. Med Clin North Am. 79(4):789-801. doi: 10.1016/s00257125(16)30039-6.

87. Knott, C., Stern, G., Wilkin, G.P., 2000. Inflammatory regulators in Parkinson's disease: iNOS, lipocortin-1, and cyclooxygenases-1 and -2. Molecular and Cellular Neuroscience. 16: 724-739. doi: 10.1006/mcne.2000.0914.

88. Koli, K., Myllärniemi, M., Keski-Oja, J., Kinnula, V.L., 2008. "Transforming growth factor- $\beta$ activation in the lung: focus on fibrosis and reactive oxygen species Antioxidants and Redox Signaling. 10 (2) 333-342. doi: 10.1089/ars.2007.1914.

89. Kurlan, R., Rothfield, K.P., Woodward, W.R., Nutt, J.G., Miller, C., Lichter, D., Shoulson, I., 1988. Erratic gastric emptying of levodopa may cause "random" fluctuations of parkinsonian mobility. Neurology. 38(3): 419-421. doi:10.1212/wnl.38.3.419.

90. Langevitz, P., Bank, I., Zemer, D., Book, M., Pras, M., 1992. Treatment of resistant rheumatoid arthritis with minocycline: an open study. J Rheumatol. 19(10):1502-4.

91. Lanza, K., Perkins, A.E., Deak, T., Bishop, C., 2019. Late aging-associated increases in L-DOPAinduced dyskinesia are accompanied by heightened neuroinflammation in the hemi-parkinsonian rat. Neurobiol Aging. 81:190-199. doi: 10.1016/j.neuroscience.2008.07.016.

92. Lazzarini, M., Martin, S., Mitkovski, M., Vozari, R.R., Stühmer, W., Bel Del, E., 2013. Doxycycline restrains glia and confers neuroprotection in a 6-OHDA Parkinson model. GLIA. 61(7):1084-100. doi: 10.1002/glia.22496.

93. Lerner, R.P., Francardo, V., Fujita, K., Bimpisidis, Z., Jourdain, V.A., Tang, C.C., Dewey, S.L., Chaly, T., Cenci, M.A., Eidelberg, D., 2017. Levodopa-induced abnormal involuntary movements correlate with altered permeability of the blood-brain-barrier in the basal ganglia. Sci Rep. 7(1):16005. doi: 10.1038/s41598-017-16228-1.

94. Liang, Y., Zhou, T., Chen, Y., Lin, D., Jing, X., Peng, S., Zheng, D., Zeng, Z., Lei, M., Wu, X., Huang, K., Yang, L., Xiao, S., Liu, J., Tao, E., 2017. Rifampicin inhibits rotenone-induced microglial inflammation via enhancement of autophagy. Neurotoxicology. 63:137-145. doi: 10.1053/j.ajkd.2016.01.020. 
95. Lin, D., Jing, X., Chen, Y., Liang, Y., Lei, M., Peng, S., Zhou, T., Zheng, D., Zeng, Z., Wu, X., Yang, L., Xiao, S., Liu, J., Tao, E., 2017. Rifampicin pre-treatment inhibits the toxicity of rotenone-induced PC12 cells by enhancing sumoylation modification of $\alpha$-synuclein. Biochem Biophys Res Commun. 485(1): 23-29. doi: 10.1016/j.bbrc.2017.01.100.

96. Lindgren, H.S., Rylander, D., Iderberg, H., Andersson, M., O'Sullivan, S.S., Williams, D.R., Lees, A.J., Cenci, M.A., 2011. Putaminal upregulation of FosB/ $\Delta$ FosB-like immunoreactivity in Parkinson's disease patients with dyskinesia. J Parkinsons Dis. 1(4):347-57. doi: 10.3233/JPD-2011-11068.

97. Liu, B., Teschemacher, A.G., Kasparov, S., 2017. Neuroprotective potential of astroglia. J Neurosci Res. 95(11):2126-2139. doi: 10.1002/jnr.24140.

98. Liu, Y., Ramamurthy, N., Marecek, J., Lee, H.M., Chen, J.L., et al., 2001. The Lipophilicity, Pharmacokinetics, and Cellular Uptake of Different Chemically-Modified Tetracyclines (CMTs). Curr Med Chem. 8: 243-252. doi: 10.2174/0929867013373525.

99. Lorenzl, S., Albers, D.S., Narr, S., Chirichigno, J., Beal, M.F., 2002. Expression of MMP-2, MMP9, and MMP-1 and their endogenous counterregulators TIMP-1 and TIMP-2 in postmortem brain tissue of Parkinson's disease. Experimental Neurology. 178(1):13-20. doi: 10.1006/exnr.2002.8019.

100. Lorenzl, S., Calingasan, N., Yang, L., Albers, D.S., Shugama, S., Gregorio, J., Krell, H.W., Chirichigno, J., Joh, T., Beal, M.F., 2004. Matrix metalloproteinase-9 is elevated in 1-methyl-4phenyl-1,2,3,6-tetrahydropyridine-induced parkinsonism in mice. Neuromolecular Med. 5(2):119-32. doi: 10.1385/NMM:5:2:119.

101. Lundblad, M., Andersson, M., Winkler, C., Kirik, D., Wierup, N., Cenci, M.A., 2002. Pharmacological validation of behavioural measures of akinesia and dyskinesia in a rat model of Parkinson's disease. European Journal of Neuroscience. 15(1):120-32. doi: 10.1046/j.0953-816x.2001.01843. x.

102. Lundblad, M., Picconi, B., Lindgren, H., Cenci, M.A., 2004. A model of L-DOPA-induced dyskinesia in 6-hydroxydopamine lesioned mice: relation to motor and cellular parameters of nigrostriatal function. Neurobiol Dis. 16(1):110-23. doi: 10.1016/j.nbd.2004.01.007.

103. Mansson, R., Hansson, M.J., Morota, S., Uchino, H., Ekdahl, C.T., Elme’rr, E., 2007. Re-evaluation of mitochondrial permeability transition as a primary neuroprotective target of minocycline. Neurobiol Dis. 25(1):198-205. doi: 10.1016/j.nbd.2006.09.008.

104. Mattappalil, A., Mergenhagen, K.A., 2014. Neurotoxicity with antimicrobials in the elderly: a review. Clin Ther. 36(11):1489-1511.e4. doi: 10.1016/j.clinthera.2014.09.020

105. McGeer, P.L., Schwab, C., Parent, A., Doudet, D., 2003. Presence of reactive microglia in monkey substantia nigra years after 1-methyl-4-phenyl-1,2,3,6-tetrahydropyridine administration. Ann Neurol. 54(5):599-604. doi: 10.1002/ana.10728.

106. Monte, A.S., Greicy, C.S., Roger, S.M., Joanna, K.S., Júnia, V.S., Rafaela, C.C., Bruna, M.M., Ribeiro, D.F., Silvânia M.M., 2013. Prevention and reversal of ketamine-induced schizophrenia related behavior by minocycline in mice: possible involvement of antioxidant and nitrergic pathway J. Psychopharmacol. 11:1032-1043. doi: 10.1177/0269881113503506.

107. Morrison, B.E., Marcondes, M.C.G., Nomura, D.K., Sanchez-Alavez, M., Sanchez-Gonzalez, A., Saar, I., et al., 2012. Cutting Edge: IL-13R 1 Expression in Dopaminergic Neurons Contributes to Their Oxidative Stress-Mediated Loss following Chronic Peripheral Treatment with Lipopolysaccharide. The Journal of Immunology. 189: 5498-5502. doi: 10.4049/jimmunol.1102150.

108. Muir, E.M., Adcock, K.H., Morgenstern, D.A., Clayton, R., von Stillfried, N., Rhodes, K., Ellis, C., Fawcett, J.W., Rogers, J.H., 2002. Matrix metalloproteases and their inhibitors are produced by overlapping populations of activated astrocytes. Brain Res Mol Brain Res. 100(1-2): 103-117. doi: 10.1016/s0169$328 \mathrm{x}(02) 00132-8$.

109. Mulas, G., Espa, E., Fenu, S., Spiga, S., Cossu, G., Pillai, E., et al., 2016. Differential induction of dyskinesia and neuroinflammation by pulsatile versus continuous L-DOPA delivery in the 6-OHDA model of Parkinson's disease. Experimental Neurology. 286: 83-92. doi: 10.1016/j.expneurol.2016.09.013.

110. Muñoz, A., Garrido-Gil, P., Dominguez-Meijide, A., Labandeira-Garcia, J.L., 2014. Angiotensin type 1 receptor blockage reduces l-dopa-induced dyskinesia in the 6-OHDA model of Parkinson's disease. Involvement of vascular endothelial growth factor and interleukin-1 $\beta$. Experimental Neurology. 261: 
720-432. doi: 10.1016/j.expneurol.2014.08.019.

111. Munzar, P., Li, H., Nicholson, K.L., Wiley, J.L., Balster, R.L., 2002. Enhancement of the discriminative stimulus effects of phencyclidine by the tetracycline antibiotics doxycycline and minocycline in rats. Psychopharmacology (Berl). 160(3):331-6. doi: 10.1007/s00213-001-0989-7.

112. Nascimento, G.C., Rizzi, E., Gerlach, R.F., Leite-Panissi, C.R.A., 2013. Expression of MMP-2 and MMP-9 in the rat trigeminal ganglion during the development of temporomandibular joint inflammation. Brazilian Journal of Medical and Biological Research. 46(11):956-967. doi: 10.1590/1414431X20133138

113. Ndlovu, B.C., Daniels, W.M.U., Mabandla, M.V., 2016. Amelioration of l-Dopa-Associated Dyskinesias with Triterpenoic Acid in a Parkinsonian Rat Model. Neurotoxicity Research. 29(1): 126-134. doi: 10.1007/s12640-015-9567-3.

114. Nikodemova, M., Duncan, I.D., Watters, J.J., 2006. Minocycline exerts inhibitory effects on multiple mitogen-activated protein kinases and $\mathrm{I} \varkappa \mathrm{B} \alpha$ degradation in a stimulus specific manner in microglia. Journal of Neurochemistry. 96(2):314-23. doi: 10.1111/j.1471-4159.2005.03520. x.

115. NINDS NET-PD Investigators. 2006. A randomized, double-blind, futility clinical trial of creatine and minocycline in early Parkinson disease. Neurology. 66(5):664-71. doi: 10.1212/01.wnl.0000201252. 57661.e1.

116. Ogier, C., Bernard, A., Chollet, A.M., Le Diguardher, T., Hanessian, S., Charton, G., Khrestchatisky, M., Rivera, S., 2006. Matrix metalloproteinase-2 (MMP-2) regulates astrocyte motility in connection with the actin cytoskeleton and integrins. Glia. 54(4):272-284. doi: 10.1002/glia.20349.

117. Ohlin, K.E., Francardo, V., Lindgren, H.S., Sillivan, S.E., O'Sullivan, S.S., Luksik, A.S., Vassoler, F.M., Lees, A.J., Konradi, C., Cenci, M.A., 2011. Vascular endothelial growth factor is upregulated by L-dopa in the parkinsonian brain: implications for the development of dyskinesia. Brain. 134(Pt 8):2339-57. doi: 10.1093/brain/awr165.

118. Ohlin, K.E., Sebastianutto, I., Adkins, C.E., Lundblad, C., Lockman, P.R., Cenci, M.A., 2012. Impact of L-DOPA treatment on regional cerebral blood flow and metabolism in the basal ganglia in a rat model of Parkinson's disease. Neuroimage. 61(1):228-39. doi: 10.1016/j.neuroimage.2012.02.066.

119. Olanow, C.W., Agid, Y., Mizuno, Y., Albanese, A., Bonuccelli, U., Damier, P., De Yebenes, J., Gershanik, O., Guttman, M., Grandas, F., Hallett, M., Hornykiewicz, O., Jenner, P., Katzenschlager, R., Langston, W.J., LeWitt, P., Melamed, E., Mena, M.A., Michel, P.P., Mytilineou, C., Obeso, J.A., Poewe, W., Quinn, N., Raisman-Vozari, R., Rajput, A.H., Rascol, O., Sampaio, C., Stocchi, F., 2004. Levodopa in the treatment of Parkinson's disease: current controversies. Mov Disord. 19(9):997-1005. doi: $10.1002 /$ mds.20243.

120. Olsson, M., Nikkhah, G., Bentlage, C., Björklund, A., 1995. Forelimb akinesia in the rat Parkinson model: differential effects of dopamine agonists and nigral transplants as assessed by a new stepping test. J Neurosci. 15(5 Pt 2):3863-75. doi: 10.1523/JNEUROSCI.15-05-03863.1995.

121. Ouchi, Y., Yoshikawa, E., Sekine, Y., Futatsubashi, M., Kanno, T., Ogusu, T., Torizuka, T., 2005. Microglial activation and dopamine terminal loss in early Parkinson's disease. Ann Neurol. 57(2):16875. doi: 10.1002/ana.20338.

122. Padovan-Neto, F.E., Cavalcanti-Kiwiatkoviski, R., Carolino, R.O.G., Anselmo-Franci, J., Del Bel, E., 2015. Effects of prolonged neuronal nitric oxide synthase inhibition on the development and expression of l-DOPA-induced dyskinesia in 6-OHDA-lesioned rats. Neuropharmacology. 89: 87-97. doi: 10.1016/j.neuropharm.2014.08.019 0028-3908.

123. Padovan-Neto, F.E., Echeverry, M.B., Tumas, V., Del-Bel, E.A., 2009. Nitric oxide synthase inhibition attenuates l-DOPA-induced dyskinesias in a rodent model of Parkinson's disease. Neuroscience. 159(3):927-35. doi: 10.1016/j.neuroscience.2009.01.034.

124. Paxinos, G., Watson, C., 2004. The Rat Brain in Stereotaxic Coordinates - The New Coronal Set. Elsevier.

125. Payne, J.B., Golub, L.M., Stoner, J.A., Lee, H.M., Reinhardt, R.A., Sorsa, T., Slepian, M.J., 2011. The effect of subantimicrobial-dose-doxycycline periodontal therapy on serum biomarkers of systemic inflammation: a randomized, double-masked, placebo-controlled clinical trial. J Am Dent Assoc. 
142(3):262-73. doi: 10.14219/jada.archive.2011.0165.

126. Picconi, B., Bagetta, V., Ghiglieri, V., Paillè, V., Di Filippo, M., Pendolino, V., Tozzi, A., Giampà, C., Fusco, F.R., Sgobio, C., Calabresi, P., 2011. Inhibition of phosphodiesterases rescues striatal long-term depression and reduces levodopa-induced dyskinesia. Brain. 134( $\mathrm{Pt} 2): 375-87$. doi: 10.1093 /brain/awq342.

127. Picconi, B., Centonze, D., Håkansson, K., Bernardi, G., 2003. Greengard P, Fisone G, Cenci MA, Calabresi P. Loss of bidirectional striatal synaptic plasticity in L-DOPA-induced dyskinesia. Nat Neurosci. 6(5):501-6. doi: 10.1038/nn1040.

128. Ramírez-García, G., Palafox-Sánchez, V., Limón, I.D., 2015. Nitrosative and cognitive effects of chronic L-DOPA administration in rats with intra-nigral 6-OHDA lesion. Neuroscience. 290:492-508. doi: 10.1016/j.neuroscience.2015.01.047.

129. Reglodi, D., Renaud, J., Tamas, A., Tizabi, Y., Socías, S.B., Del-Bel, E., Raisman-Vozari R., 2017. Novel tactics for neuroprotection in Parkinson's disease: Role of antibiotics, polyphenols and neuropeptides. Progress in Neurobiology. 155:120-148. doi: 10.1016/j.pneurobio.2015.10.004.

130. Robinson, T.E., Becker, J.B., 1983. The rotational behavior model: asymmetry in the effects of unilateral 6-OHDA lesions of the substantia nigra in rats. Brain Res. 28;264(1):127-31. doi: 10.1016/00068993(83)91129-0.

131. Röhl, C., Lucius, R., Sievers, J., 200. The effect of activated microglia on astrogliosis parameters in astrocyte cultures. Brain Research. 238(1): 64-70. doi: 10.1016/j.brainres.2006.10.057.

132. Santa-Cecília, F.V., Leite, C.A., Del-Bel, E., Raisman-Vozari, R., 2019. The Neuroprotective Effect of Doxycycline on Neurodegenerative Diseases. Neurotox Res. 35(4):981-986. doi: 10.3389/fphar.2019.00738

133. Schlesinger, F.K. Krampfl, G., Haeseler, R., Dengler, J., 2004. Bufler Competitive and open channel block of recombinant nAChR channels by different antibiotics Neuromuscul. Disord. 14:307-312. doi: 10.1213/00000539-200004000-00036.

134. Sian, J., Dexter, D.T., Lees, A.J., Daniel, S., Agid, Y., Javoy-Agid, F., et al., 1994. Alterations in glutathione levels in Parkinson's disease and other neurodegenerative disorders affecting basal ganglia. Annals of Neurology. 36(3):348-55. doi: 10.1002/ana.410360305.

135. Sidoryk-Wegrzynowicz, M., Wegrzynowicz, M., Lee, E., Bowman, A. B., \& Aschner, M. 2011. Role of astrocytes in brain function and disease. Toxicologic Pathology. 39:115-123. doi: $10.1177 / 0192623310385254$.

136. Socias, S.B., González-Lizárraga, F., Avila, C.L., Vera, C., Acuña, L., Sepulveda-Diaz, J.E., Del-Bel, E., Raisman-Vozari, R., Chehin, R.N., 2018. Exploiting the therapeutic potential of ready-to-use drugs: Repurposing antibiotics against amyloid aggregation in neurodegenerative diseases. Prog Neurobiol. 162:17-36. doi: 10.1016/j.pneurobio.2017.12.002.

137. Sofroniew, M.V., Vinters, H.V., 2010. Astrocytes: Biology and pathology. Acta Neuropathol. 119: 7-35. doi: 10.1007/s00401-009-0619-8.

138. Solís, O., Espadas, I., Del-Bel, E.A., Moratalla, R., 2015. Nitric oxide synthase inhibition decreases l-DOPA-induced dyskinesia and the expression of striatal molecular markers in Pitx3-/- aphakia mice. Neurobiology of Disease. 73:49-59. doi: 10.1016/j.nbd.2014.09.010.

139. Somogyi, P., Takagi, H., 1982. A note on the use of picric acid-paraformaldehydeglutaraldehyde fixative for correlated light and electron microscopic immunocytochemistry. Neuroscience. 7: 1779-1783. doi: 10.1016/0306-4522(82)90035-5.

140. Spinnewyn, B., Mautino, G., Marin, J.G., Rocher, M.N., Grandoulier, A.S., Ferrandis, E., et al., 2011. BN82451 attenuates l-dopa-induced dyskinesia in 6-OHDA-lesioned rat model of Parkison's disease. Neuropharmacology. 60(4): 692-700. doi: 10.1016/j.neuropharm.2010.11.019.

141. Stephenson, J., Nutma, E., van der Valk, P., Amor, S., 2018. Inflammation in CNS neurodegenerative diseases. Immunology. 154(2):204-219. doi: 10.1111/imm.12922

142. Stoilova, T., Colombo, L., Forloni, G., Tagliavini, F., Salmona, M., 2013. A new face for old antibiotics: tetracyclines in treatment of amyloidoses. J Med Chem. 56(15):5987-6006. doi: 10.1021/jm400161p.

143. Tansey, M.G., McCoy, M.K., Frank-Cannon, T.C., 2007. Neuroinflammatory mechanisms in Parkin- 
son's disease: potential environmental triggers, pathways, and targets for early therapeutic intervention. Exp Neurol. 208(1):1-25. doi: 10.1016/j.expneurol.2007.07.004.

144. Teema, A.M., Zaitone, S.A., Moustafa, Y.M., 2016. Ibuprofen or piroxicam protects nigral neurons and delays the development of l-dopa induced dyskinesia in rats with experimental Parkinsonism: Influence on angiogenesis. Neuropharmacology. 107: 432-450. doi: 10.1016/j.neuropharm.2016.03.034.

145. Teismann, P., Tieu, K., Choi, D.K., Wu. D.C., Naini, A., Hunot, S., et al., 2003. Cyclooxygenase-2 is instrumental in Parkinson's disease neurodegeneration. Proceedings of the National Academy of Sciences. 100(9):5473-5478. doi: 10.1073/pnas.0837397100.

146. Tekumalla, P.K., Calon, F., Rahman, Z., Birdi, S., Rajput, A.H., Hornykiewicz, O., Di Paolo, T., Bédard, P.J., Nestler, E.J., 2001. Elevated levels of DeltaFosB and RGS9 in striatum in Parkinson's disease. Biol Psychiatry. 15;50(10):813-6. doi: 10.1016/s0006-3223(01)01234-3.

147. Ungerstedt, U., Arbuthnott, G.W., 1970. Quantitative recording of rotational behavior in rats after 6-hydroxy-dopamine lesions of the nigrostriatal dopamine system. Brain Res. 18;24(3):485-93. doi: 10.1016/0006-8993(70)90187-3.

148. Vijayakumar, D., Jankovic, J., 2016. Drug-Induced Dyskinesia, Part 1: Treatment of Levodopa-Induced Dyskinesia. Drugs. 76(7):759-77. doi: 10.1007/s40265-016-0566-3.

149. Weng, J.C., Tikhonova, M.A., Chen, J.H., Shen, M.S., Meng, W.Y., Chang, Y.T., Chen, K.H., Liang, K.C., Hung, C.S., Amstislavskaya, T.G., Ho. Y.J., 2016. Ceftriaxone prevents the neurodegeneration and decreased neurogenesis seen in a Parkinson's disease rat model: An immunohistochemical and MRI study. Behav Brain Res. 05:126-39. doi: 10.1016/j.bbr.2016.02.034.

150. Winkler, C., Kirik, D., Björklund, A., Cenci, M.A., 2002. L-DOPA-induced dyskinesia in the intrastriatal 6-hydroxydopamine model of Parkinson's disease: Relation to motor and cellular parameters of nigrostriatal function. Neurobiology of Disease. 10(2):165-86. doi: 10.1006/nbdi.2002.0499.

151. Wolf, S.A., Boddeke, H.W., Kettenmann, H., 2017. Microglia in Physiology and Disease. Annu Rev Physiol. 79:619-643. doi: 10.1146/annurev-physiol-022516-034406.

152. Worlitzer, M.M..A, Viel, T., Jacobs, A.H., Schwamborn, J.C., 2013. The majority of newly generated cells in the adult mouse substantia nigra express low levels of Doublecortin, but their proliferation is unaffected by 6-OHDA-induced nigral lesion or Minocycline-mediated inhibition of neuroinflammation. European Journal of Neuroscience. 38(5):2684-92. doi: 10.1111/ejn.12269.

153. Wu, D.C., Teismann, P., Tieu, K., Vila, M., Jackson-Lewis, V., Ischiropoulos, H., et al., 2003. NADPH oxidase mediates oxidative stress in the 1-methyl-4-phenyl-1,2,3,6- tetrahydropyridine model of Parkinson's disease. Proceedings of the National Academy of Sciences. 100(10):6145-50. doi: 10.1073/pnas.0937239100

154. Wu, X., Liang, Y., Jing, X., Lin, D., Chen, Y., Zhou, T., Peng, S., Zheng, D., Zeng, Z., Lei, M., Huang, K., Tao, E., 2018. Rifampicin Prevents SH-SY5Y Cells from Rotenone-Induced Apoptosis via the PI3K/Akt/GSK-3ß/CREB Signaling Pathway. Neurochem Res. 43(4):886-893. doi: 10.1007/s11064018-2494-y.

155. Yimer, E.M., Hishe, H.Z., Tuem, K.B., 2019. Repurposing of the $\beta$-Lactam Antibiotic, Ceftriaxone for Neurological Disorders: A Review. Front Neurosci. 13:236. doi: 10.3389/fnins.2019.00236.

156. You, H., Mariani, L.L., Mangone, G., Le Febvre de Nailly, D., Charbonnier-Beaupel, F., Corvol, J.C., 2018. Molecular basis of dopamine replacement therapy and its side effects in Parkinson's disease. Cell Tissue Res. 373(1):111-135. doi: 10.1007/s00441-018-2813-2.

157. Yuhas, Y., Berent, E., Cohen, R., Ashkenazi, S., 2009. Role of NF-kappaB activation and peroxisome proliferator-activated receptor gamma inhibition in the effect of rifampin on inducible nitric oxide synthase transcription in human lung epithelial cells. Antimicrob. Agents Chemother. 53: 1539-1545. doi: 10.1128/AAC.00961-08.

158. Yulug, B., Hanoglu, L., Kilic, E., Schabitz, W.R., 2014. RIFAMPICIN: an antibiotic with brain protective function. Brain Res Bull. 107: 37-42. doi: 10.1016/j.brainresbull.2014.05.007.

159. Zhang, G.B., Feng, Y.H., Wang, P.Q., Song, J.H., Wang, P., Wang, S.A., 2015. A study on the protective role of doxycycline upon dopaminergic neuron of LPS-PD rat model rat. European Review for Medical and Pharmacological Sciences. 19(18):3468-74. 
160. Zhang, L., Shirayama, Y., Shimizu, E., Iyo, M., Hashimoto, K., 2006. Protective effects of minocycline on 3,4-methylenedioxymethamphetamine-induced neurotoxicity in serotonergic and dopaminergic neurons of mouse brain. Eur J Pharmacol. 544(1-3):1-9. doi: 10.1016/j.ejphar.2006.05.047.

161. Zhou, C., Huang, Y., Przedborski, S., 2008. Oxidative stress in Parkinson's disease: a mechanism of pathogenic and therapeutic significance. Ann N Y Acad Sci. 1147: 93-104. doi:10.1196/annals.1427.023.

Supplementary Table 1 - Open Field Data ${ }^{\text {a }}$

\begin{tabular}{|c|c|c|c|}
\hline TREATMENTS & $\begin{array}{l}\text { LOCOMOTOR } \\
\text { ACTIVITY }(\mathrm{m})\end{array}$ & $\begin{array}{l}\text { LOCOMOTOR } \\
\text { ACTIVITY }(\mathrm{m})\end{array}$ & $\begin{array}{l}\text { TIME OF IMMOBILITY } \\
\text { (s) }\end{array}$ \\
\hline ACUTE DOX & ACUTE DOX & ACUTE DOX & ACUTE DOX \\
\hline No- & No- & $68.3 \pm 2.3^{*}$ & $232.7 \pm 12.1^{*}$ \\
\hline lesion+vehicle+vehicle & lesion+vehicle+vehicle & & \\
\hline $\begin{array}{l}6- \\
\text { OHDA+vehicle+vehicle }\end{array}$ & $\begin{array}{l}\text { 6- } \\
\text { OHDA+vehicle+vehicle }\end{array}$ & $12.7 \pm 1.4$ & $387.3 \pm 26.1$ \\
\hline 6- & $6-$ & $12.5 \pm 1.7$ & $395.4 \pm 32.6$ \\
\hline \multicolumn{4}{|c|}{ OHDA+doxycycline+vehicleOHDA+doxycycline+vehicle } \\
\hline $\begin{array}{l}\text { 6-OHDA+vehicle+L- } \\
\text { DOPA }\end{array}$ & $\begin{array}{l}\text { 6-OHDA+vehicle+L- } \\
\text { DOPA }\end{array}$ & $42.2 \pm 4.9^{*}$ & $229.8 \pm 16.2^{*}$ \\
\hline $6-$ & $6-$ & $38.1 \pm 4.0^{*}$ & $218.5 \pm 29.5^{*}$ \\
\hline $\begin{array}{l}\text { OHDA +doxycycline }+\mathrm{L}- \\
\text { DOPA }\end{array}$ & $\begin{array}{l}\text { OHDA+doxycycline+L- } \\
\text { DOPA }\end{array}$ & & \\
\hline CHRONIC DOX & CHRONIC DOX & CHRONIC DOX & CHRONIC DOX \\
\hline $\begin{array}{l}\text { No-lesion+chronic- } \\
\text { vehicle+vehicle }\end{array}$ & $\begin{array}{l}\text { No-lesion+chronic- } \\
\text { vehicle+vehicle }\end{array}$ & $45.3 \pm 4.2^{*}$ & $114.8 \pm 13.1^{*}$ \\
\hline $\begin{array}{l}\text { 6-OHDA+chronic- } \\
\text { vehicle+vehicle }\end{array}$ & $\begin{array}{l}\text { 6-OHDA+chronic- } \\
\text { vehicle+vehicle }\end{array}$ & $9.8 \pm 1.6$ & $349.4 \pm 52.6$ \\
\hline $\begin{array}{l}\text { 6-OHDA+chronic- } \\
\text { doxycycline+vehicle }\end{array}$ & $\begin{array}{l}\text { 6-OHDA+chronic- } \\
\text { doxycycline+vehicle }\end{array}$ & $9.3 \pm 1.8$ & $472.3 \pm 20.4$ \\
\hline $\begin{array}{l}\text { 6-OHDA+chronic- } \\
\text { vehicle+L-DOPA }\end{array}$ & $\begin{array}{l}\text { 6-OHDA+chronic- } \\
\text { vehicle+L-DOPA }\end{array}$ & $28.2 \pm 3.9^{*}$ & $130.1 \pm 50.3^{*}$ \\
\hline $\begin{array}{l}\text { 6-OHDA+chronic- } \\
\text { doxycycline+L-DOPA }\end{array}$ & $\begin{array}{l}\text { 6-OHDA+chronic- } \\
\text { doxycycline+L-DOPA }\end{array}$ & $25.7 \pm 5.4^{*}$ & $144.4 \pm 42.2^{*}$ \\
\hline ACUTE COL-3 & ACUTE COL-3 & ACUTE COL-3 & ACUTE COL-3 \\
\hline $6-$ & $6-$ & $11.6 \pm 7.1$ & $315.1 \pm 31.2$ \\
\hline OHDA+vehicle+vehicle & OHDA+vehicle+vehicle & & \\
\hline $\begin{array}{l}\text { 6-OHDA+COL- } \\
3+\text { vehicle }\end{array}$ & $\begin{array}{l}\text { 6-OHDA+COL- } \\
3+\text { vehicle }\end{array}$ & $13.2 \pm 5.1$ & $303.4 \pm 25.1$ \\
\hline $\begin{array}{l}\text { 6-OHDA+vehicle+L- } \\
\text { DOPA }\end{array}$ & $\begin{array}{l}\text { 6-OHDA+vehicle+L- } \\
\text { DOPA }\end{array}$ & $26.9 \pm 3.8^{*}$ & $127 \pm 13.2^{*}$ \\
\hline $\begin{array}{l}\text { 6-OHDA+COL-3+L- } \\
\text { DOPA }\end{array}$ & $\begin{array}{l}\text { 6-OHDA+COL-3+L- } \\
\text { DOPA }\end{array}$ & $27.8 \pm 4.4^{*}$ & $128 \pm 16.4^{*}$ \\
\hline
\end{tabular}

a Measures of spread from data observed in the open field task. TWO-WAY ANOVA followed by Bonferroni post hoc test; $\mathrm{n}=6$-7per group. Data are expressed as the mean $\pm \mathrm{SEM}$; $\mathrm{p}<0.05{ }^{*}$ compared to 6-OHDA+vehicle+vehicle and 6-OHDA+doxycycline+vehicle. ANOVA, analysis of variance; 6-OHDA, 6Hydroxydopamine; ch, chronic; DOX, doxycycline; COL-3, CMT-3,6-demethyl-6-deoxy-4-de[dimethylamino]; L-DOPA, L-3,4-dihydroxyphenylalanine; VEH, Vehicle.

Supplementary Table 2 - Statistical analysis performed in this study ${ }^{\mathrm{b}}$. 


\begin{tabular}{|c|c|c|c|c|}
\hline & $\begin{array}{l}O N E-W A Y \\
A N O V A\end{array}$ & $\begin{array}{l}O N E-W A Y \\
A N O V A\end{array}$ & $\begin{array}{l}O N E-W A Y \\
A N O V A\end{array}$ & $\begin{array}{l}O N E-W A Y \\
A N O V A\end{array}$ \\
\hline Parameter & Treatment & Treatment & Treatment & Treatment \\
\hline $\begin{array}{l}\text { Stepping test - } \\
\text { acute doxycycline } \\
\text { (Fig. 1-C) }\end{array}$ & $\begin{array}{l}\mathrm{F}(4,43)=6.51 \mathbf{P} \\
<\mathbf{0 . 0 0 1}\end{array}$ & $\begin{array}{l}\mathrm{F}(4,43)=6.51 \mathbf{P} \\
<\mathbf{0 . 0 0 1}\end{array}$ & $\begin{array}{l}\mathrm{F}(4,43)=6.51 \mathbf{P} \\
<\mathbf{0 . 0 0 1}\end{array}$ & $\begin{array}{l}\mathrm{F}(4,43)=6.51 \mathbf{P} \\
<\mathbf{0 . 0 0 1}\end{array}$ \\
\hline $\begin{array}{l}\text { Time of immobility } \\
\text { in the open field - } \\
\text { acute doxycycline } \\
\text { (Fig. 1-D) }\end{array}$ & $\begin{array}{l}\mathrm{F}(4,43)=11.92 \mathbf{P} \\
<\mathbf{0 . 0 0 0 1}\end{array}$ & $\begin{array}{l}\mathrm{F}(4,43)=11.92 \mathbf{P} \\
<\mathbf{0 . 0 0 0 1}\end{array}$ & $\begin{array}{l}\mathrm{F}(4,43)=11.92 \mathbf{P} \\
<\mathbf{0 . 0 0 0 1}\end{array}$ & $\begin{array}{l}\mathrm{F}(4,43)=11.92 \mathbf{P} \\
<\mathbf{0 . 0 0 0 1}\end{array}$ \\
\hline $\begin{array}{l}\text { Distance travelled } \\
\text { in the open field - } \\
\text { acute doxycycline } \\
\text { (Supplementary } \\
\text { table 1) }\end{array}$ & $\begin{array}{l}\mathrm{F}(4,43)=39.02 \mathbf{P} \\
<\mathbf{0 . 0 0 0 1}\end{array}$ & $\begin{array}{l}\mathrm{F}(4,43)=39.02 \mathbf{P} \\
<\mathbf{0 . 0 0 0 1}\end{array}$ & $\begin{array}{l}\mathrm{F}(4,43)=39.02 \mathbf{P} \\
<\mathbf{0 . 0 0 0 1}\end{array}$ & $\begin{array}{l}\mathrm{F}(4,43)=39.02 \mathbf{P} \\
<\mathbf{0 . 0 0 0 1}\end{array}$ \\
\hline $\begin{array}{l}\text { Time of immobility } \\
\text { in the open field - } \\
\text { acute COL-3 } \\
\text { (Supplementary } \\
\text { table 1) }\end{array}$ & $\begin{array}{l}\mathrm{F}(1,16)=17.278 \\
\mathbf{P}<\mathbf{0 . 0 0 1}\end{array}$ & $\begin{array}{l}\mathrm{F}(1,16)=17.278 \\
\mathbf{P}<\mathbf{0 . 0 0 1}\end{array}$ & $\begin{array}{l}\mathrm{F}(1,16)=17.278 \\
\mathbf{P}<\mathbf{0 . 0 0 1}\end{array}$ & $\begin{array}{l}\mathrm{F}(1,16)=17.278 \\
\mathbf{P}<\mathbf{0 . 0 0 1}\end{array}$ \\
\hline $\begin{array}{l}\text { Distance travelled } \\
\text { in the open field - } \\
\text { acute COL-3 } \\
\text { (Supplementary } \\
\text { table 1) }\end{array}$ & $\begin{array}{l}\mathrm{F}(1,18)=18.32 \mathbf{P} \\
<\mathbf{0 . 0 0 1}\end{array}$ & $\begin{array}{l}\mathrm{F}(1,18)=18.32 \mathbf{P} \\
<\mathbf{0 . 0 0 1}\end{array}$ & $\begin{array}{l}\mathrm{F}(1,18)=18.32 \mathbf{P} \\
<\mathbf{0 . 0 0 1}\end{array}$ & $\begin{array}{l}\mathrm{F}(1,18)=18.32 \mathbf{P} \\
<\mathbf{0 . 0 0 1}\end{array}$ \\
\hline $\begin{array}{l}\text { ROS - acute } \\
\text { doxycycline (Fig. } \\
\text { 3-G) }\end{array}$ & $\begin{array}{l}\mathrm{F}(2,15)=50.46 \\
\mathbf{P}<\mathbf{0 . 0 0 0 1}\end{array}$ & $\begin{array}{l}\mathrm{F}(2,15)=50.46 \\
\mathbf{P}<\mathbf{0 . 0 0 0 1}\end{array}$ & $\begin{array}{l}\mathrm{F}(2,15)=50.46 \\
\mathbf{P}<\mathbf{0 . 0 0 0 1}\end{array}$ & $\begin{array}{l}\mathrm{F}(2,15)=50.46 \\
\mathbf{P}<\mathbf{0 . 0 0 0 1}\end{array}$ \\
\hline $\begin{array}{l}\text { Gelatinolytic } \\
\text { activity - acute } \\
\text { doxycycline (Fig. } \\
\text { 3-I) }\end{array}$ & $\begin{array}{l}\mathrm{F}(2,16)=153.4 \mathbf{P} \\
<\mathbf{0 . 0 0 0 1}\end{array}$ & $\begin{array}{l}\mathrm{F}(2,16)=153.4 \mathbf{P} \\
<\mathbf{0 . 0 0 0 1}\end{array}$ & $\begin{array}{l}\mathrm{F}(2,16)=153.4 \mathbf{P} \\
<\mathbf{0 . 0 0 0 1}\end{array}$ & $\begin{array}{l}\mathrm{F}(2,16)=153.4 \mathbf{P} \\
<\mathbf{0 . 0 0 0 1}\end{array}$ \\
\hline $\begin{array}{l}\text { MMP-3 - acute } \\
\text { doxycycline (Fig. } \\
\text { 3-K) }\end{array}$ & $\begin{array}{l}\mathrm{F}(2,16)=584.0 \mathbf{P} \\
<\mathbf{0 . 0 0 0 1}\end{array}$ & $\begin{array}{l}\mathrm{F}(2,16)=584.0 \mathbf{P} \\
<\mathbf{0 . 0 0 0 1}\end{array}$ & $\begin{array}{l}\mathrm{F}(2,16)=584.0 \mathbf{P} \\
<\mathbf{0 . 0 0 0 1}\end{array}$ & $\begin{array}{l}\mathrm{F}(2,16)=584.0 \mathbf{P} \\
<\mathbf{0 . 0 0 0 1}\end{array}$ \\
\hline $\begin{array}{l}\text { ROS - chronic } \\
\text { doxycycline (Fig. } \\
\text { 4-I) }\end{array}$ & $\begin{array}{l}\mathrm{F}(2,14)=611.7 \\
\mathbf{P}<\mathbf{0 . 0 0 0 1}\end{array}$ & $\begin{array}{l}\mathrm{F}(2,14)=611.7 \\
\mathbf{P}<\mathbf{0 . 0 0 0 1}\end{array}$ & $\begin{array}{l}\mathrm{F}(2,14)=611.7 \\
\mathbf{P}<\mathbf{0 . 0 0 0 1}\end{array}$ & $\begin{array}{l}\mathrm{F}(2,14)=611.7 \\
\mathbf{P}<\mathbf{0 . 0 0 0 1}\end{array}$ \\
\hline $\begin{array}{l}\text { Gelatinolytic } \\
\text { activity - chronic } \\
\text { doxycycline (Fig. } \\
\text { 4-K) }\end{array}$ & $\begin{array}{l}\mathrm{F}(2,16)=100.3 \mathbf{P} \\
<\mathbf{0 . 0 0 0 1}\end{array}$ & $\begin{array}{l}\mathrm{F}(2,16)=100.3 \mathbf{P} \\
<\mathbf{0 . 0 0 0 1}\end{array}$ & $\begin{array}{l}\mathrm{F}(2,16)=100.3 \mathbf{P} \\
<\mathbf{0 . 0 0 0 1}\end{array}$ & $\begin{array}{l}\mathrm{F}(2,16)=100.3 \mathbf{P} \\
<\mathbf{0 . 0 0 0 1}\end{array}$ \\
\hline $\begin{array}{l}\text { MMP-2 - acute } \\
\text { doxycycline } \\
\text { (Supplementary } \\
\text { Fig. 4-A) }\end{array}$ & $\begin{array}{l}\mathrm{F}(2,15)=0.1948 \\
\mathbf{P}=\mathbf{0 . 8 2}\end{array}$ & $\begin{array}{l}\mathrm{F}(2,15)=0.1948 \\
\mathbf{P}=\mathbf{0 . 8 2}\end{array}$ & $\begin{array}{l}\mathrm{F}(2,15)=0.1948 \\
\mathbf{P}=\mathbf{0 . 8 2}\end{array}$ & $\begin{array}{l}\mathrm{F}(2,15)=0.1948 \\
\mathbf{P}=\mathbf{0 . 8 2}\end{array}$ \\
\hline $\begin{array}{l}\text { MMP-9 - acute } \\
\text { doxycycline }\end{array}$ & $\begin{array}{l}\mathrm{F}(2,15)=6.408 \mathbf{P} \\
<\mathbf{0 . 0 0 1}\end{array}$ & $\begin{array}{l}\mathrm{F}(2,15)=6.408 \mathbf{P} \\
<\mathbf{0 . 0 0 1}\end{array}$ & $\begin{array}{l}\mathrm{F}(2,15)=6.408 \mathbf{P} \\
<\mathbf{0 . 0 0 1}\end{array}$ & $\begin{array}{l}\mathrm{F}(2,15)=6.408 \mathbf{P} \\
<\mathbf{0 . 0 0 1}\end{array}$ \\
\hline
\end{tabular}

(Supplementary

Fig. 4-B) 


\begin{tabular}{|c|c|c|c|c|}
\hline & $\begin{array}{l}\text { ONE-WAY } \\
A N O V A\end{array}$ & $\begin{array}{l}\text { ONE-WAY } \\
A N O V A\end{array}$ & $\begin{array}{l}O N E-W A Y \\
A N O V A\end{array}$ & $\begin{array}{l}\text { ONE-WAY } \\
A N O V A\end{array}$ \\
\hline $\begin{array}{l}\text { MMP-2 chronic } \\
\text { doxycycline } \\
\text { (Supplementary } \\
\text { Fig. 4-C) }\end{array}$ & $\begin{array}{l}\mathrm{F}(2,15)=9.828 \mathbf{P} \\
<\mathbf{0 . 0 1}\end{array}$ & $\begin{array}{l}\mathrm{F}(2,15)=9.828 \mathbf{P} \\
<\mathbf{0 . 0 1}\end{array}$ & $\begin{array}{l}\mathrm{F}(2,15)=9.828 \mathbf{P} \\
<\mathbf{0 . 0 1}\end{array}$ & $\begin{array}{l}\mathrm{F}(2,15)=9.828 \mathbf{P} \\
<\mathbf{0 . 0 1}\end{array}$ \\
\hline \multirow[t]{2}{*}{$\begin{array}{l}\text { MMP-9 chronic } \\
\text { doxycycline } \\
\text { (Supplementary } \\
\text { Fig. 4-D) }\end{array}$} & $\begin{array}{l}\mathrm{F}(2,15)=49.83 \mathbf{P} \\
<\mathbf{0 . 0 0 0 1}\end{array}$ & $\begin{array}{l}\mathrm{F}(2,15)=49.83 \mathbf{P} \\
<\mathbf{0 . 0 0 0 1}\end{array}$ & $\begin{array}{l}\mathrm{F}(2,15)=49.83 \mathbf{P} \\
<\mathbf{0 . 0 0 0 1}\end{array}$ & $\begin{array}{l}\mathrm{F}(2,15)=49.83 \mathbf{P} \\
<\mathbf{0 . 0 0 0 1}\end{array}$ \\
\hline & $\begin{array}{l}R M O N E-W A Y \\
A N O V A\end{array}$ & $\begin{array}{l}R M O N E-W A Y \\
A N O V A\end{array}$ & $\begin{array}{l}R M O N E-W A Y \\
A N O V A\end{array}$ & $\begin{array}{l}R M O N E-W A Y \\
A N O V A\end{array}$ \\
\hline Parameter & Treatment & Treatment & Treatment & Treatment \\
\hline $\begin{array}{l}\text { AIMs - acute } \\
\text { doxycycline (Fig. } \\
\text { 1-A) }\end{array}$ & $\begin{array}{l}\mathrm{F}(3,30)=11.07 \\
\mathbf{P}<\mathbf{0 . 0 0 0 1}\end{array}$ & $\begin{array}{l}\mathrm{F}(3,30)=11.07 \\
\mathbf{P}<\mathbf{0 . 0 0 0 1}\end{array}$ & $\begin{array}{l}\mathrm{F}(3,30)=11.07 \\
\mathbf{P}<\mathbf{0 . 0 0 0 1}\end{array}$ & $\begin{array}{l}\mathrm{F}(3,30)=11.07 \\
\mathbf{P}<\mathbf{0 . 0 0 0 1}\end{array}$ \\
\hline $\begin{array}{l}\text { AIMs - acute } \\
\text { COL-3 (Fig. 5-A) }\end{array}$ & $\begin{array}{l}\mathrm{F}(1,549,9,294)= \\
23.87 \mathbf{P}<\mathbf{0 . 0 0 1} \\
T W O-W A Y \\
A N O V A\end{array}$ & $\begin{array}{l}\mathrm{F}(1,549,9,294)= \\
23.87 \mathbf{P}<\mathbf{0 . 0 0 1} \\
T W O-W A Y \\
A N O V A\end{array}$ & $\begin{array}{l}\mathrm{F}(1,549,9,294)= \\
23.87 \mathbf{P}<\mathbf{0 . 0 0 1} \\
T W O-W A Y \\
A N O V A\end{array}$ & $\begin{array}{l}\mathrm{F}(1,549,9,294)= \\
23.87 \mathbf{P}<\mathbf{0 . 0 0 1} \\
T W O-W A Y \\
A N O V A\end{array}$ \\
\hline Parameter & $\begin{array}{l}L-D O P A \\
\text { Treatment }\end{array}$ & $\begin{array}{l}\text { Doxycycline } \\
\text { Treatment }\end{array}$ & $\begin{array}{l}\text { Doxycycline } \\
\text { Treatment }\end{array}$ & Interaction \\
\hline $\begin{array}{l}\text { FOS-B - acute } \\
\text { doxycycline (Fig. } \\
2-\mathrm{C})\end{array}$ & $\begin{array}{l}\mathrm{F}(1,16)=54.06 \mathbf{P} \\
<\mathbf{0 . 0 0 0 1}\end{array}$ & $\begin{array}{l}\mathrm{F}(1,16)=2.832 \mathbf{P} \\
=\mathbf{0 . 1 1 1 8}\end{array}$ & $\begin{array}{l}\mathrm{F}(1,16)=2.832 \mathbf{P} \\
=\mathbf{0 . 1 1 1 8}\end{array}$ & $\begin{array}{l}\mathrm{F}(1,16)=6.609 \mathbf{P} \\
<\mathbf{0 . 0 5}\end{array}$ \\
\hline $\begin{array}{l}\text { COX-2 - acute } \\
\text { doxycycline (Fig. } \\
2-F)\end{array}$ & $\begin{array}{l}\mathrm{F}(1,19)=13.33 \mathbf{P} \\
<\mathbf{0 . 0 1}\end{array}$ & $\begin{array}{l}\mathrm{F}(1,19)=0.5967 \\
\mathbf{P}=\mathbf{0 . 4 5}\end{array}$ & $\begin{array}{l}\mathrm{F}(1,19)=0.5967 \\
\mathbf{P}=\mathbf{0 . 4 5}\end{array}$ & $\begin{array}{l}\mathrm{F}(1,19)=6.744 \mathbf{P} \\
<\mathbf{0 . 0 5}\end{array}$ \\
\hline $\begin{array}{l}\text { OX- } 42 \text { - acute } \\
\text { doxycycline (Fig. } \\
\text { 2-L) }\end{array}$ & $\begin{array}{l}\mathrm{F}(1,22)=106.5 \mathbf{P} \\
<\mathbf{0 . 0 0 0 1}\end{array}$ & $\begin{array}{l}\mathrm{F}(1,22)=14.63 \mathbf{P} \\
<\mathbf{0 . 0 0 1}\end{array}$ & $\begin{array}{l}\mathrm{F}(1,22)=14.63 \mathbf{P} \\
<\mathbf{0 . 0 0 1}\end{array}$ & $\begin{array}{l}\mathrm{F}(1,22)=7.140 \mathbf{P} \\
<\mathbf{0 . 0 5}\end{array}$ \\
\hline $\begin{array}{l}\text { GFAP - acute } \\
\text { doxycycline (Fig. } \\
\text { 2-I) }\end{array}$ & $\begin{array}{l}\mathrm{F}(1,22)=98.57 \\
\mathbf{P}<\mathbf{0 . 0 0 0 1}\end{array}$ & $\begin{array}{l}\mathrm{F}(1,22)=44.26 \\
\mathbf{P}<\mathbf{0 . 0 0 0 1}\end{array}$ & $\begin{array}{l}\mathrm{F}(1,22)=44.26 \\
\mathbf{P}<\mathbf{0 . 0 0 0 1}\end{array}$ & $\begin{array}{l}\mathrm{F}(1,22)=8.810 \\
\mathbf{P}<\mathbf{0 . 0 1}\end{array}$ \\
\hline $\begin{array}{l}\text { Distance travelled } \\
\text { in the open field - } \\
\text { chronic doxycycline } \\
\text { (Supplementary } \\
\text { table 1) }\end{array}$ & $\begin{array}{l}\mathrm{F}(1,21)=21.11 \mathbf{P} \\
<\mathbf{0 . 0 1}\end{array}$ & $\begin{array}{l}\mathrm{F}(1,21)=0.153 \mathbf{P} \\
=\mathbf{0 . 8 9}\end{array}$ & $\begin{array}{l}\mathrm{F}(1,21)=0.153 \mathbf{P} \\
=\mathbf{0 . 8 9}\end{array}$ & $\begin{array}{l}F(1,21)=0.07 \mathbf{P} \\
=\mathbf{0 . 7 9}\end{array}$ \\
\hline \multirow{2}{*}{$\begin{array}{l}\text { Time of immobility } \\
\text { in the open field - } \\
\text { chronic doxycycline } \\
\text { (Supplementary } \\
\text { table 1) }\end{array}$} & $\begin{array}{l}\mathrm{F}(1,21)=39.76 \mathbf{P} \\
<\mathbf{0 . 0 0 0 1}\end{array}$ & $\begin{array}{l}\mathrm{F}(1,21)=2.500 \mathbf{P} \\
=\mathbf{0 . 1 3}\end{array}$ & $\begin{array}{l}\mathrm{F}(1,21)=2.500 \mathbf{P} \\
=\mathbf{0 . 1 3}\end{array}$ & $\begin{array}{l}\mathrm{F}(1,21)=1.563 \mathbf{P} \\
=\mathbf{0 . 2 2}\end{array}$ \\
\hline & $\begin{array}{l}R M T W O-W A Y \\
A N O V A\end{array}$ & $\begin{array}{l}R M T W O-W A Y \\
A N O V A\end{array}$ & $\begin{array}{l}R M T W O-W A Y \\
A N O V A\end{array}$ & $\begin{array}{l}R M T W O-W A Y \\
A N O V A\end{array}$ \\
\hline $\begin{array}{l}\text { Parameter } \\
\text { Time course of } \\
\text { AIMs - acute }\end{array}$ & $\begin{array}{l}\text { Treatment } \\
\mathrm{F}(1,10)=15.17 \mathbf{P} \\
<\mathbf{0 . 0 0 0 1}\end{array}$ & $\begin{array}{l}\text { Time } \\
\mathrm{F}(9,90)=23.17 \mathbf{P} \\
=\mathbf{0 . 0 0 3}\end{array}$ & $\begin{array}{l}\text { Time } \\
\mathrm{F}(9,90)=23.17 \mathbf{P} \\
=\mathbf{0 . 0 0 3}\end{array}$ & $\begin{array}{l}\text { Interaction } \\
\mathrm{F}(9,90)=9.42 \mathbf{P} \\
<\mathbf{0 . 0 0 0 1}\end{array}$ \\
\hline
\end{tabular}

doxycycline (Fig.

1-B) 


\begin{tabular}{|c|c|c|c|c|}
\hline & $\begin{array}{l}O N E-W A Y \\
A N O V A\end{array}$ & $\begin{array}{l}O N E-W A Y \\
A N O V A\end{array}$ & $\begin{array}{l}O N E-W A Y \\
A N O V A\end{array}$ & $\begin{array}{l}O N E-W A Y \\
A N O V A\end{array}$ \\
\hline $\begin{array}{l}\text { AIMs - chronic } \\
\text { doxycycline (Fig. } \\
\text { 4-A) }\end{array}$ & $\begin{array}{l}\mathrm{F}(1,30)=492 \mathbf{P} \\
<\mathbf{0 . 0 0 0 1}\end{array}$ & $\begin{array}{l}\mathrm{F}(2,32)=22.92 \mathbf{P} \\
<\mathbf{0 . 0 0 0 1}\end{array}$ & $\begin{array}{l}\mathrm{F}(2,32)=22.92 \mathbf{P} \\
<\mathbf{0 . 0 0 0 1}\end{array}$ & $\begin{array}{l}\mathrm{F}(2,30)=23.31 \mathbf{P} \\
<\mathbf{0 . 0 0 0 1}\end{array}$ \\
\hline $\begin{array}{l}\text { Time course of } \\
\text { AIMs - chronic } \\
\text { doxycycline (Fig. } \\
\text { 4-B) }\end{array}$ & $\begin{array}{l}\mathrm{F}(1,10)=746.3 \mathbf{P} \\
<\mathbf{0 . 0 0 0 1}\end{array}$ & $\begin{array}{l}\mathrm{F}(9,90)=68.03 \mathbf{P} \\
<\mathbf{0 . 0 0 0 1}\end{array}$ & $\begin{array}{l}\mathrm{F}(9,90)=68.03 \mathbf{P} \\
<\mathbf{0 . 0 0 0 1}\end{array}$ & $\begin{array}{l}\mathrm{F}(9,90)=63.26 \mathbf{P} \\
<\mathbf{0 . 0 0 0 1}\end{array}$ \\
\hline \multirow[t]{2}{*}{$\begin{array}{l}\text { Time course of } \\
\text { AIMs - acute } \\
\text { COL-3 (Fig. 5-B) }\end{array}$} & $\begin{array}{l}\mathrm{F}(1,63)=36.19 \mathbf{P} \\
<\mathbf{0 . 0 0 0 1}\end{array}$ & $\begin{array}{l}\mathrm{F}(8,63)=13.01 \mathbf{P} \\
<\mathbf{0 . 0 0 0 1}\end{array}$ & $\begin{array}{l}\mathrm{F}(8,63)=13.01 \mathbf{P} \\
<\mathbf{0 . 0 0 0 1}\end{array}$ & $\begin{array}{l}\mathrm{F}(8,63)=2.974 \mathbf{P} \\
=\mathbf{0 . 0 0 6 9}\end{array}$ \\
\hline & $\begin{array}{l}\text { PAIRED } \\
\text { T-TEST }\end{array}$ & $\begin{array}{l}\text { PAIRED } \\
T-T E S T\end{array}$ & $\begin{array}{l}\text { PAIRED } \\
\text { T-TEST }\end{array}$ & $\begin{array}{l}\text { PAIRED } \\
\text { T-TEST }\end{array}$ \\
\hline Parameter & Effect & Effect & Effect & Effect \\
\hline Axial, Limb and & Axial: & Axial: & Limb: & Orofacial: \\
\hline Orofacial measures & $\mathrm{T}=1.401$ & $\mathrm{~T}=1.401$ & $\mathrm{~T}=4.422$ & $\mathrm{~T}=2.767$ \\
\hline $\begin{array}{l}\text { AIMs - acute } \\
\text { doxycycline } \\
\text { (Supplementary } \\
\text { Fig. 2-A, -B and } \\
\text {-C) }\end{array}$ & $\mathrm{P}<0.05$ & $\mathrm{P}<0.05$ & $\mathrm{P}=0.0013$ & $\mathrm{P}=0.0199$ \\
\hline Axial, Limb and & Axial: & Axial: & Limb: & Orofacial: \\
\hline Orofacial measures & $\mathrm{T}=3.590$ & $\mathrm{~T}=3.590$ & $\mathrm{~T}=4.216$ & $\mathrm{~T}=4.657$ \\
\hline $\begin{array}{l}\text { AIMs - chronic } \\
\text { doxycycline } \\
\text { (Supplementary } \\
\text { Fig. 2-D, -E and -F) }\end{array}$ & $\mathrm{P}<0.05$ & $\mathrm{P}<0.05$ & $\mathrm{P}=0.00012$ & $\mathrm{P}=0.0023$ \\
\hline Axial, Limb and & Axial: & Axial: & Limb: & Orofacial: \\
\hline Orofacial measures & $\mathrm{T}=3.738$ & $\mathrm{~T}=3.738$ & $\mathrm{~T}=5.259$ & $\mathrm{~T}=2.214$ \\
\hline $\begin{array}{l}\text { AIMs - COL-3 } \\
\text { (Supplementary } \\
\text { Fig. 2-G, -H and -I) }\end{array}$ & $\mathrm{P}=0.0022$ & $\mathrm{P}=0.0022$ & $\mathrm{P}=0.0001$ & $\mathrm{P}<0.05$ \\
\hline
\end{tabular}




\begin{tabular}{|c|c|c|c|c|}
\hline & $\begin{array}{l}O N E-W A Y \\
A N O V A\end{array}$ & $\begin{array}{l}O N E-W A Y \\
A N O V A\end{array}$ & $\begin{array}{l}O N E-W A Y \\
A N O V A\end{array}$ & $\begin{array}{l}O N E-W A Y \\
A N O V A\end{array}$ \\
\hline $\begin{array}{l}\text { b Parametric } \\
\text { statistical } \\
\text { analyses carried } \\
\text { out to calculate } \\
\text { measures of } \\
\text { spread from data } \\
\text { observed in this } \\
\text { study. ANOVA, } \\
\text { analysis of } \\
\text { variance; COL-3, } \\
\text { CMT-3,6- } \\
\text { demethyl-6- } \\
\text { deoxy-4- } \\
\text { de[dimethylamino]- } \\
\text { tetracycline } \\
\text { formerly known } \\
\text { as Incyclinide; } \\
\text { COX-2, } \\
\text { Cyclooxygenase-2; } \\
\text { F, F statistic; } \\
\text { FOS-B, protein } \\
\text { FOS-B; GFAP, } \\
\text { Glial fibrillary } \\
\text { acidic protein; } \\
\text { MMP, Matrix } \\
\text { metalloproteinase; } \\
\text { OX-42, CD11b/c } \\
\text { equivalent protein } \\
\text { of microglia; P, P } \\
\text { value; RM, } \\
\text { repeated } \\
\text { measures; ROS, } \\
\text { reactive oxygen } \\
\text { species; t, t value } \\
\text { in the student's } \\
\text { t-test. }\end{array}$ & $\begin{array}{l}\text { b Parametric } \\
\text { statistical } \\
\text { analyses carried } \\
\text { out to calculate } \\
\text { measures of } \\
\text { spread from data } \\
\text { observed in this } \\
\text { study. ANOVA, } \\
\text { analysis of } \\
\text { variance; COL-3, } \\
\text { CMT-3,6- } \\
\text { demethyl-6- } \\
\text { deoxy-4- } \\
\text { de[dimethylamino]- } \\
\text { tetracycline } \\
\text { formerly known } \\
\text { as Incyclinide; } \\
\text { COX-2, } \\
\text { Cyclooxygenase-2; } \\
\text { F, F statistic; } \\
\text { FOS-B, protein } \\
\text { FOS-B; GFAP, } \\
\text { Glial fibrillary } \\
\text { acidic protein; } \\
\text { MMP, Matrix } \\
\text { metalloproteinase; } \\
\text { OX-42, CD11b/c } \\
\text { equivalent protein } \\
\text { of microglia; P, P } \\
\text { value; RM, } \\
\text { repeated } \\
\text { measures; ROS, } \\
\text { reactive oxygen } \\
\text { species; t, t value } \\
\text { in the student's } \\
\text { t-test. }\end{array}$ & $\begin{array}{l}\text { b Parametric } \\
\text { statistical } \\
\text { analyses carried } \\
\text { out to calculate } \\
\text { measures of } \\
\text { spread from data } \\
\text { observed in this } \\
\text { study. ANOVA, } \\
\text { analysis of } \\
\text { variance; COL-3, } \\
\text { CMT-3,6- } \\
\text { demethyl-6- } \\
\text { deoxy-4- } \\
\text { de[dimethylamino]- } \\
\text { tetracycline } \\
\text { formerly known } \\
\text { as Incyclinide; } \\
\text { COX-2, } \\
\text { Cyclooxygenase-2; } \\
\text { F, F statistic; } \\
\text { FOS-B, protein } \\
\text { FOS-B; GFAP, } \\
\text { Glial fibrillary } \\
\text { acidic protein; } \\
\text { MMP, Matrix } \\
\text { metalloproteinase; } \\
\text { OX-42, CD11b/c } \\
\text { equivalent protein } \\
\text { of microglia; P, P } \\
\text { value; RM, } \\
\text { repeated } \\
\text { measures; ROS, } \\
\text { reactive oxygen } \\
\text { species; t, t value } \\
\text { in the student's } \\
\text { t-test. }\end{array}$ & $\begin{array}{l}\text { b Parametric } \\
\text { statistical } \\
\text { analyses carried } \\
\text { out to calculate } \\
\text { measures of } \\
\text { spread from data } \\
\text { observed in this } \\
\text { study. ANOVA, } \\
\text { analysis of } \\
\text { variance; COL-3, } \\
\text { CMT-3,6- } \\
\text { demethyl-6- } \\
\text { deoxy-4- } \\
\text { de[dimethylamino]- } \\
\text { tetracycline } \\
\text { formerly known } \\
\text { as Incyclinide; } \\
\text { COX-2, } \\
\text { Cyclooxygenase-2; } \\
\text { F, F statistic; } \\
\text { FOS-B, protein } \\
\text { FOS-B; GFAP, } \\
\text { Glial fibrillary } \\
\text { acidic protein; } \\
\text { MMP, Matrix } \\
\text { metalloproteinase; } \\
\text { OX-42, CD11b/c } \\
\text { equivalent protein } \\
\text { of microglia; P, P } \\
\text { value; RM, } \\
\text { repeated } \\
\text { measures; ROS, } \\
\text { reactive oxygen } \\
\text { species; t, t value } \\
\text { in the student's } \\
\text { t-test. }\end{array}$ & $\begin{array}{l}\text { b Parametric } \\
\text { statistical } \\
\text { analyses carried } \\
\text { out to calculate } \\
\text { measures of } \\
\text { spread from data } \\
\text { observed in this } \\
\text { study. ANOVA, } \\
\text { analysis of } \\
\text { variance; COL-3, } \\
\text { CMT-3,6- } \\
\text { demethyl-6- } \\
\text { deoxy-4- } \\
\text { de[dimethylamino] } \\
\text { tetracycline } \\
\text { formerly known } \\
\text { as Incyclinide; } \\
\text { COX-2, } \\
\text { Cyclooxygenase-2; } \\
\text { F, F statistic; } \\
\text { FOS-B, protein } \\
\text { FOS-B; GFAP, } \\
\text { Glial fibrillary } \\
\text { acidic protein; } \\
\text { MMP, Matrix } \\
\text { metalloproteinase; } \\
\text { OX-42, CD11b/c } \\
\text { equivalent protein } \\
\text { of microglia; P, P } \\
\text { value; RM, } \\
\text { repeated } \\
\text { measures; ROS, } \\
\text { reactive oxygen } \\
\text { species; t, t value } \\
\text { in the student's } \\
\text { t-test. }\end{array}$ \\
\hline
\end{tabular}

Supplementary Table 3 - Antibody details

c

\begin{tabular}{|c|c|c|c|c|c|c|c|}
\hline $\begin{array}{l}\text { Primary } \\
\text { antibodies }\end{array}$ & $\begin{array}{l}\text { Primary } \\
\text { antibodies }\end{array}$ & $\begin{array}{l}\text { Primary } \\
\text { antibodies }\end{array}$ & $\begin{array}{l}\text { Primary } \\
\text { antibodies }\end{array}$ & $\begin{array}{l}\text { Secondary } \\
\text { antibodies }\end{array}$ & $\begin{array}{l}\text { Secondary } \\
\text { antibodies }\end{array}$ & $\begin{array}{l}\text { Secondary } \\
\text { antibodies }\end{array}$ & $\begin{array}{l}\text { Secondary } \\
\text { antibodies }\end{array}$ \\
\hline Antigen & Host & Dilution & Manufac & Antigen & Host & Dilution & Type \\
\hline & rabbit & $1: 1000$ & US & $(\mathrm{H}+\mathrm{L})$ & goat & $1: 400$ & Biotinylated \\
\hline Т9237-13 & & & Biological & rabbit & & & \\
\hline FOS-B & rabbit & $1: 4000$ & Santa & $(\mathrm{H}+\mathrm{L})$ & goat & $1: 400$ & Biotinylated \\
\hline H-75: & & & Cruz & rabbit & & & \\
\hline
\end{tabular}

sc-7203 


\begin{tabular}{|c|c|c|c|c|c|c|c|}
\hline $\begin{array}{l}\text { Primary } \\
\text { antibodies }\end{array}$ & $\begin{array}{l}\text { Primary } \\
\text { antibodies }\end{array}$ & $\begin{array}{l}\text { Primary } \\
\text { antibodies }\end{array}$ & $\begin{array}{l}\text { Primary } \\
\text { antibodies }\end{array}$ & $\begin{array}{l}\text { Secondary } \\
\text { antibodies }\end{array}$ & $\begin{array}{l}\text { Secondary } \\
\text { antibodies }\end{array}$ & $\begin{array}{l}\text { Secondary } \\
\text { antibodies }\end{array}$ & $\begin{array}{l}\text { Secondary } \\
\text { antibodies }\end{array}$ \\
\hline $\begin{array}{l}\text { COX-2 } \\
160126\end{array}$ & rabbit & $1: 1000$ & Cayman & $\begin{array}{l}(\mathrm{H}+\mathrm{L}) \\
\text { rabbit }\end{array}$ & goat & $1: 400$ & Biotinylated \\
\hline $\begin{array}{l}\text { OX-42 } \\
\text { Ab1211 }\end{array}$ & mouse & $1: 600$ & Abcam & $\begin{array}{l}(\mathrm{H}+\mathrm{L}) \\
\text { mouse }\end{array}$ & horse & $1: 400$ & Biotinylated \\
\hline $\begin{array}{l}\text { GFAP } \\
\text { G6171 }\end{array}$ & rabbit & $1: 4000$ & Sigma & $\begin{array}{l}(\mathrm{H}+\mathrm{L}) \\
\text { rabbit }\end{array}$ & goat & $1: 400$ & Biotinylated \\
\hline $\begin{array}{l}\text { MMP-3 } \\
\text { SAB4501892 }\end{array}$ & rabbit & $1: 1000$ & Sigma & $\begin{array}{l}(\mathrm{H}+\mathrm{L}) \\
\text { rabbit }\end{array}$ & horse & $1: 400$ & HRP \\
\hline
\end{tabular}

c Antibodies used in immunohistochemistry and western blotting procedures. TH, tyrosine hydroxylase; FOS-B, protein Fo

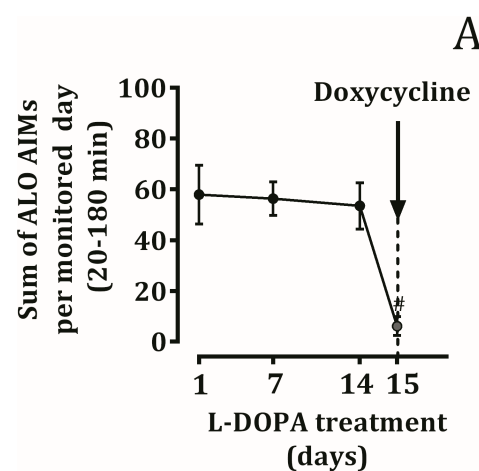

A
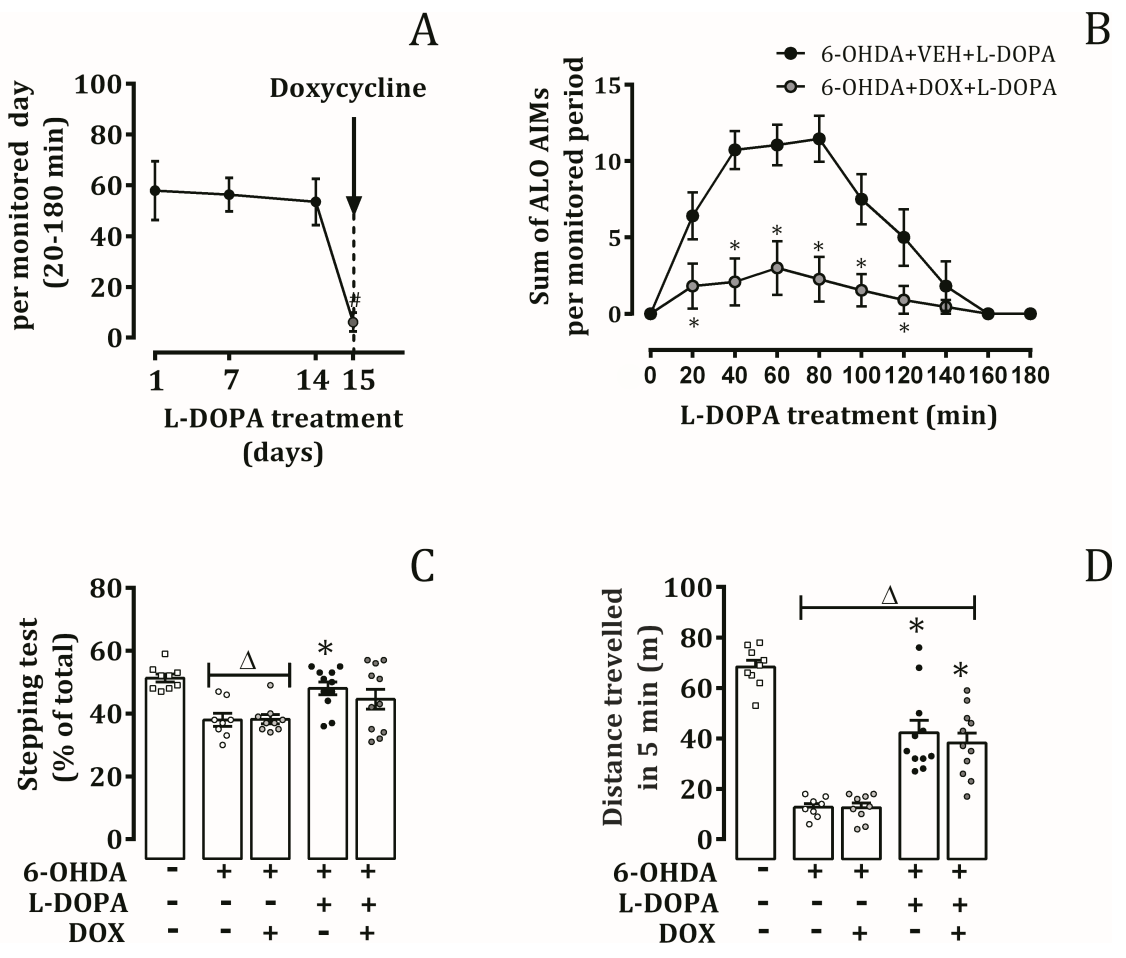

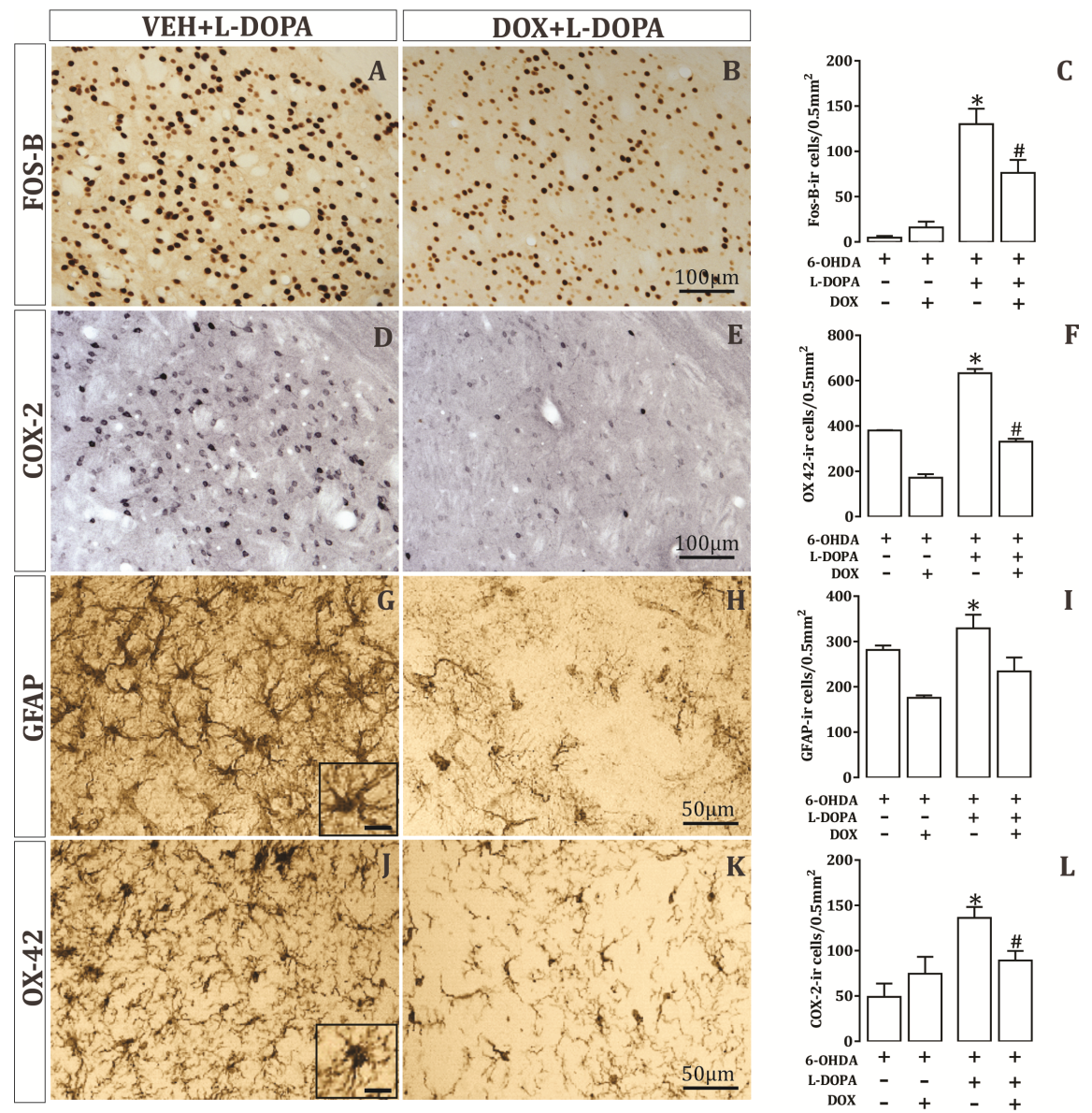

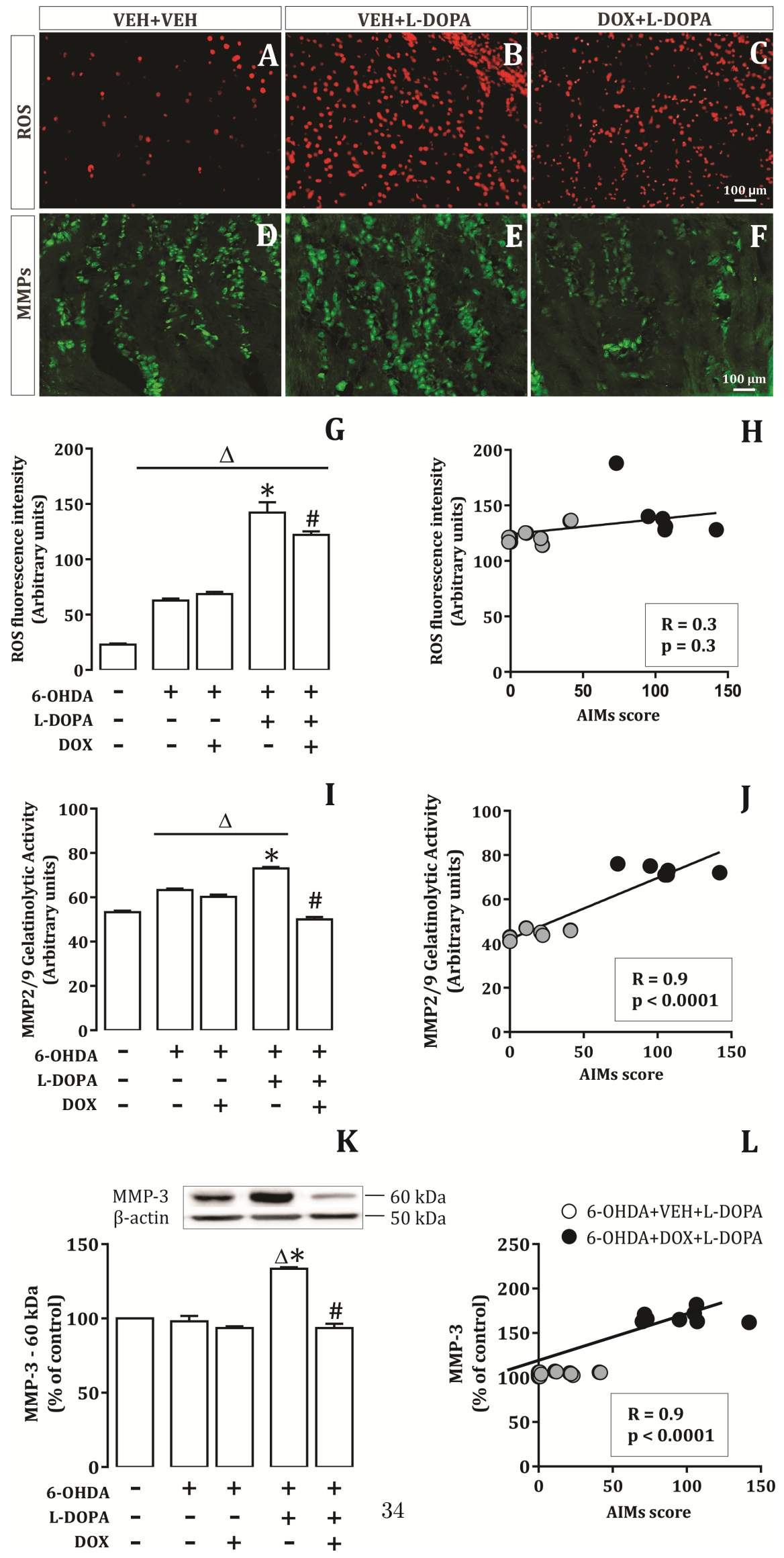


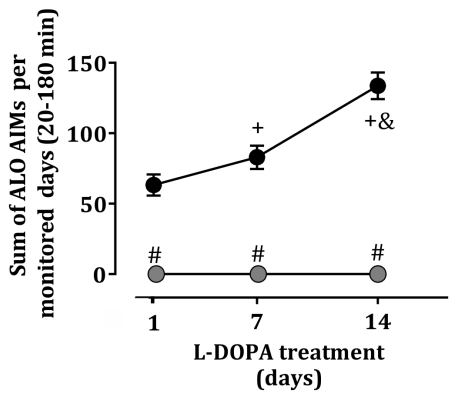

A
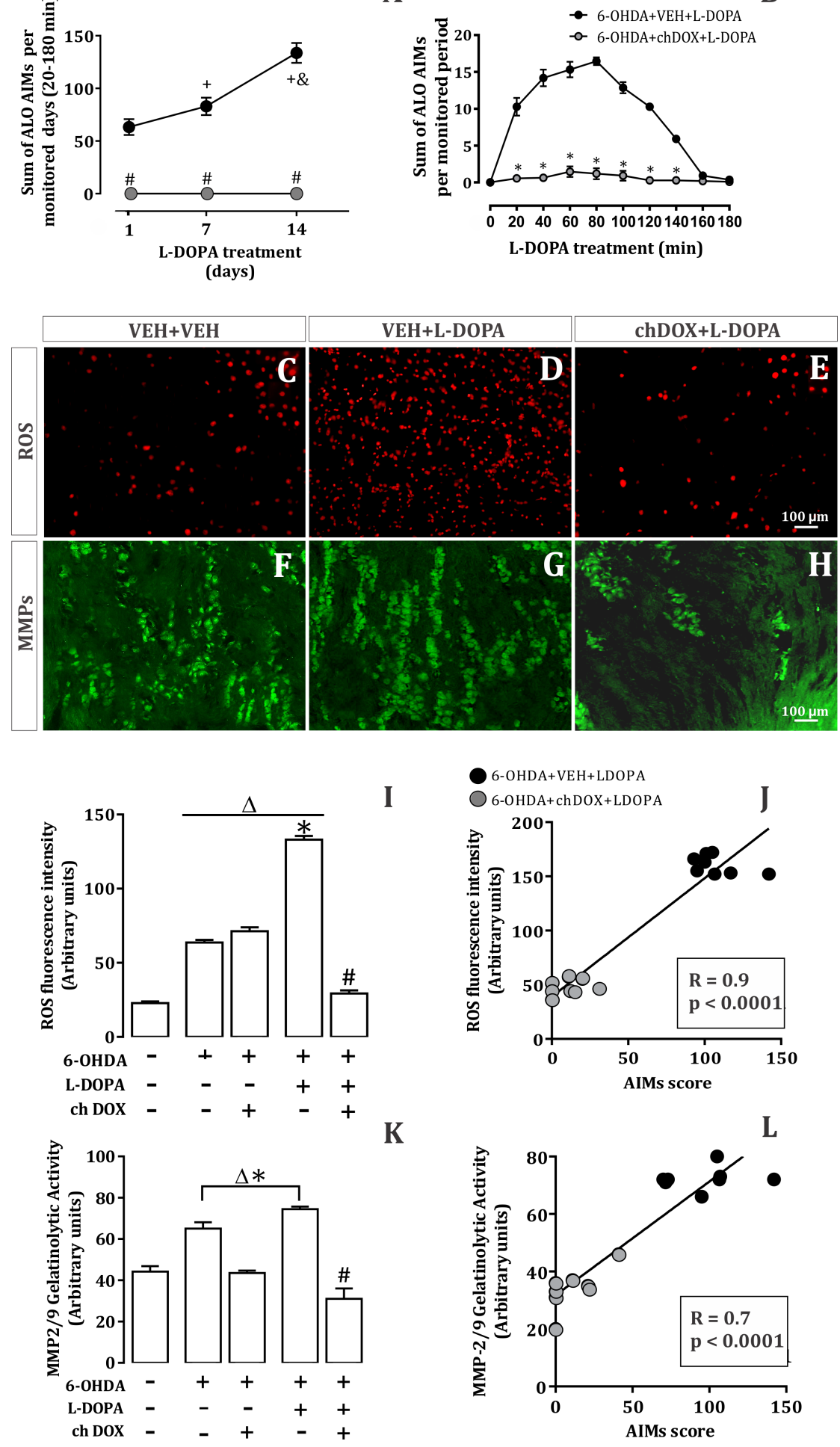


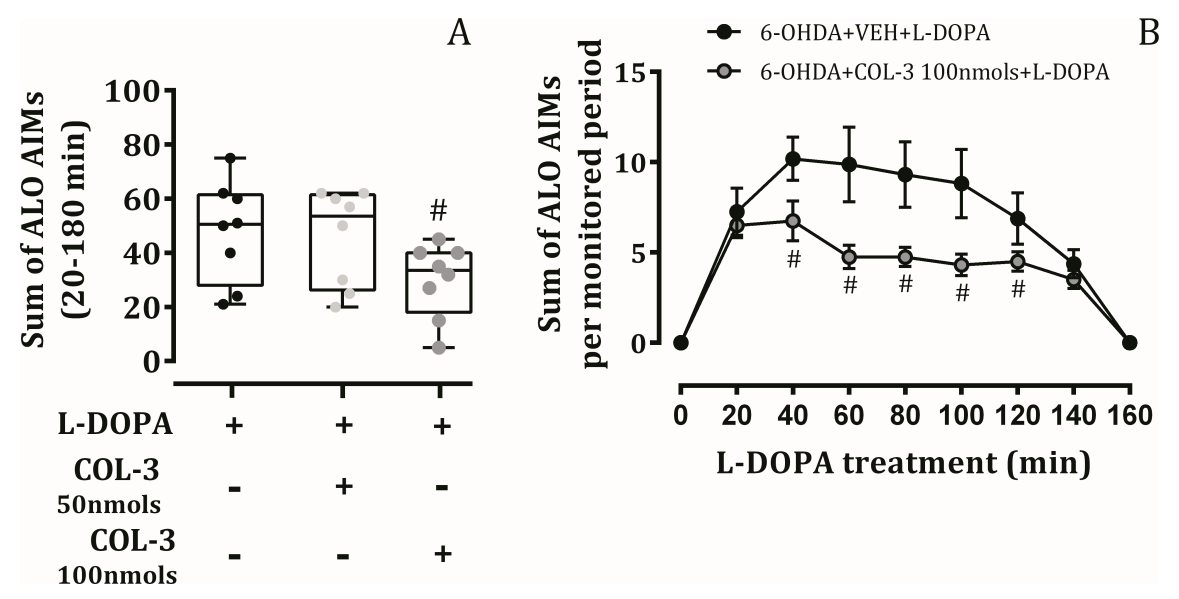

